\title{
Searching for Political Fiscal Cycles in Hungary
}

\author{
Endrit Lami ${ }^{1,2}$, Drini Imami ${ }^{3}$
}

ABSTRACT Hungary has had a remarkably high public debt throughout the transition, and it has continued to
increase during recent years, exceeding $80 \%$ of the GDP. Its debt and fiscal deficit were the highest
among the Visegrád countries during the transition. One factor triggering the debt increase may be
elections-related fiscal policies. By analyzing quarterly data for Hungary, we found clear empirical
evidence of fiscal expansion before elections and contractions afterwards. These events are widely
known as political fiscal cycles. We observed statistically significant incremental increases in fiscal
deficits as elections approach, both in nominal and in GDP ratios, followed by contractions after
elections. Thus, it can be concluded that incumbents in Hungary are engaged in opportunistic
political fiscal cycles by embracing expansionary fiscal policy before parliamentary elections. Our
findings also suggest that political fiscal cycles in Hungary may be an underlying factor contribut-
ing to the accumulation of public debt.

KEY WORDS: political fiscal cycles; deficit; Hungary

JEL Classification: $\quad$ O12; L20; M21; J24

'Budapest University of Technology and Economics (BME), Hungary,

${ }^{2}$ Ministry of Finance - Macroeconomic Policy Department, Albania

${ }^{3}$ Agriculture University of Tirana, Albania

\section{Introduction}

According to the opportunistic political business cycles (PBC) theory that was originally developed by Nordhaus (1975), the incumbent engages in expansionary economic policies and behaves in an opportunistic manner before an election to increase the likelihood of winning. The Nordhaus political business cycle theory asserts that governments stimulate economic growth before elections, thus benefiting from the short-run Philips curve and price rigidities in the short term. Inflation increases after an election because of the preelection economic expansion. After elections, incum-

Correspondence concerning this article should be addressed to: Drini Imami, Agriculture University of Tirana, Universiteti Bujqesor iTiranes, Koder-Kamez, Tirana 1001 Albania.E-mail:dimami@ubt.edu.al bents revert to tight economic policies to stabilize or reduce inflation.

An alternative view is the partisan $\mathrm{PBC}$ theory, which substantially differs from the opportunistic PBC theory because the former is based upon an ideological approach rather than on an opportunistic approach focused only on the incumbent's re-election. Hibbs (1977) assumes that, in general, political parties in most industrialized countries are distinguished, to a large extent, by class, income and related socioeconomic characteristics. According to Hibbs, left wing, labor oriented governments pursue different policies than right wing governments because they have different preferences towards macroeconomic variables, including unemployment and inflation. Within both the opportunistic and the partisan frameworks, rational expectations were later introduced by several authors 
such as Cukierman \& Meltzer (1986), Rogoff and Sibert (1988), and Person and Tabellini (1990) for rational opportunistic models and Alesina (1987), Alesina and Rosenthal (1995) for rational partisan models. ${ }^{1}$ However, voters' rational behaviors can be questioned for new democracies due to a lack of voter experience with respect to competitive elections. The opportunistic and partisan PBC models, however, despite the differences, are not mutually exclusive, as it is rational for the incumbent to be motivated by both ideological differences and opportunistic behavior simultaneously.

Over the last two decades, this field of political economy has been enriched by a significant amount of empirical research. While initially the focus of PBC related empirical research was on Western countries, over the last decade, there has been a growing interest in PBC - with a special focus on economic policy rather than economic outcomes - on developing and/ or transition countries whose institutions, economies and societies differ significantly from those of developed Western countries (Shi \& Svensson, 2003). Shi and Svensson (2002) find evidence of significant preelectoral decreases in the fiscal balance in developing and developed countries, while Hallenberg, de Souza and Clark (2002) prove the existence of PBC, both fiscal and monetary instruments, in EU accession countries. Asutay (2004) provides evidence for the presence of opportunistic PBC in Turkey, while Imami \& Lami (2006) show clear evidence of PBC in Albania with the expansion of several main public budgetary expenditures as well as decreases in unemployment before elections and normalization or contractions afterwards. On the other hand, Block (2002) analyzes rational opportunistic PBC theory and the fiscal expansion before elections in African countries. Brender and Dazen (2005) empirically show that new democracies are particularly vulnerable to political budgetary cycles, while Alt and Lassen (2006) claim that electoral cycles in fiscal balance are more a feature related to the level of fiscal transparency and the level of political polarization rather than the state of the democracy. Meanwhile, Shi and Svensson (2006) identify the aspect of information asymmetry among voters and the incumbents' rents of staying in power to be relevant factors in explaining political budget cycles.

The framework of an opportunistic PBC is considered relevant not only for developing/transition countries but also for developed countries - the opportunistic cycle theory regarding government spending inclinations has been observed in Germany (Galli \& Rossi, 2002), and with respect to lower fiscal balance, it has been observed in several OECD developed countries with weaker fiscal transparency(Alt \&Lassen, 2006).

Hungary has had remarkably high debt throughout the transition, and it had the largest fiscal deficit during the transition of all Visegrád group countries. The Hungarian debt has continued to increase during the last several years, exceeding $80 \%$ of the GDP and prompting the European Union to suspend funds of $495 \mathrm{~m}$ euros ( $\$ 655 \mathrm{~m} ; £ 417 \mathrm{~m}$ ) due to the country’s budget deficit. This is the first case of the EU taking action over the budget deficit of any of its members (BBC, 2012). Despite the recent attempt by the government to curb public spending, debt is still high and remains a major concern for the Hungarian economy. Furthermore, there are concerns that the government may follow expansionary economic policies prior to the 2014 elections (Than \& Szakacs, 2012), which may trigger increasing of debt.

The Hungarian political system provides a basis for a strong government that can more easily persuade fiscal expansionary policies. The Hungarian parliament is unicameral, meaning it does not have an upper chamber. Furthermore, the President does not have veto power over legislative proposals. Therefore, as long as the government holds the majority in the parliament, it can easily pursue its fiscal policies (Haggard, Kaufman, \& Shugart, 2001). In the last two elections, the winning party received the necessary majority in the parliament to establish a government with its own votes; thus, there was no need for a coalition, a situation that may be favorable political ground for conducting PFC (see Streb, Lema, \& Torrens, 2009). The lack of strict and practically enforced fiscal rules in Hungary may have also been a supporting factor for PFC, as was the case for a panel of American states according to Rose (2005).

The objective of our work is to identify the possible existence of political fiscal (or budget) cycles (PFC) in Hungary based on an opportunistic PBC framework. Given Hungary's political and economic history, its institutional organization, its macroeconomic developments during the last two decades of democracy and its 

tion. Based on their results, Streb et al. (2012) argue that temporal aggregation, which is inherent in annual data, is a strong underlying factor that accounts for the non-evidence of PBC in most of the existing empirical research on developed countries. Opposite-sign shifts in fiscal policy within less than a year of elections offset each other, and consequently, $\mathrm{PBC}$ is underestimated if annual data are used. Akhmedov and Zhuravskaya (2004) are even more critical of the inter-annual frequency of the time series. In their monthly panel data study that investigated opportunistic PBC in a set of regions in Russia, they argue that even analyses based on quarterly data tend to underestimate the PBC. They find that with respect to Russia, only with monthly frequency data is it possible to correctly estimate the magnitude and timing of generally short-lived but sizable election-related cycles.

In addition to overcoming this potential deficiency of temporal aggregation that is inherent in annual data, we could analyze election effects on the fiscal policy through two different time perspectives by utilizing quarterly time series. First, we could adopt the common approach of analyzing possible opportunistic electoral effects on fiscal deficit during different quarterly cumulative time intervals around elections, ranging from one quarter to eight cumulative quarters (two years) before and after elections. Second, we could adopt another approach, which, to the best of our knowledge, has not been used in the existing empirical research on PFC. This second approach aims to analyze possible electorally driven shifts of fiscal policy (fiscal deficit) during different yearly time windows before and after elections. We do this by creating yearly political dummy variables ( $P D y$ ) (to be explained in the next sub-section). On the one hand, this new approach avoids the potential problem of temporal aggregation, given that the specification of yearly time intervals around elections is not constrained by the calendar year reference of the data (the case of annual time series) because now the reference is to the election itself. On the other hand, this new approach still allows us to analyze and derive conclusions based on the more intuitive yearly time perspective of possible existing PFCs in Hungary.

The available quarterly time series we employ spans from the first quarter of 1999 to the second quarter of 2012, for 54 observations. The data are denominated in billions of Hungarian Forint (HUF). All observations of general government fiscal balance in Hungary result in an fiscal deficit (negative balance), except for Q1-2011. The fiscal balance experienced a high surplus in the first quarter of 2011 due to one-off revenues received from transferring mandatory private pension fund assets and employee contributions from the private pillar of the pension system back to the government ownership. Therefore, we omitted the outlier observation for Q1-2011 from the statistical analysis. In addition to nominal values (in HUF billions), we also analyzed the fiscal deficit measured as a percentage ratio of nominal GDP, which allows us to control for nominal effects of economic growth and inflation.

Three parliamentary elections took place during the aforementioned time series span and were fully captured by the empirical methodology applied. Specifically, the elections were held on the $4^{\text {th }}$ of April, 2002 with a second round on the $21^{\text {st }}$ of April; on the $9^{\text {th }}$ of April, 2006 with a second round on the $23^{\text {rd }}$ of April and on the $11^{\text {th }}$ of April, 2010 with a second round on the $25^{\text {th }}$ of April. Another parliamentary election partially captured in our analysis is that of the $10^{\text {th }}$ of May, 1998 with a second round on the $24^{\text {th }}$ of May.

There are two other parliamentary elections held earlier during the pluralist history of Hungary. The first was held in March 1990 and the second in May 1994. Neither of these elections was covered in our analysis as there are no available quarterly fiscal data before 1999 in any of the public sources.

\subsection{Econometrical approach}

Following the standard approach in this area of research, we apply the intervention analysis based on Box and Tiao (1975), which is known as the Box-Tiao approach. This approach has been applied in several similar works on this subject, such as McCallum (1978), Hibbs (1987), Alesina and Sachs (1988), and Alesina and Roubini (1992). Basically, the test proceeds by subjecting the time series of interest variables to a Box-Tiao intervention analysis by modeling them through the most appropriate autoregressivemoving average (ARMA) and an intervention variable where the intervention variable models the time distance to the election day and captures the effect of the elections on the variable of interest. The intervention variable can also be a $V$-shaped dummy variable 
designed to mimic the cyclical behavior of the variable of interest throughout a full incumbent electoral tenure. A simple formal representation of the variable of interest $\left(z_{t}\right)$ that is subject to the intervention analysis is the following:

$z_{t}=\mu+I_{t}+N_{t}$

where $\mu$ denotes the mean level of the variable time series, the term $I_{t}$ denotes the intervention effect due to a specific event (parliamentary elections) and $N_{t}$ denotes the noise of the time series. The last term $\left(N_{t}\right)$ is modeled using a suitable ARMA $(p, q)$ model:

$N_{t}=\phi_{1} N_{t-1}+\ldots+\phi_{p} N_{t-p}+E_{t}-\theta_{1} E_{t-1}+\ldots+\theta_{p} E_{t-q}$

where $E_{t}$ denotes an independent error sequence. The simplest term, which corresponds to the t-test in a non-time series setting, is the intervention term/variable. In this case, the intervention variable takes the form of a pulse intervention, meaning an abrupt jump in the series followed by a gradual decline at the normal level of the series. The pulse intervention term can be formally expressed as:

$I_{t}=\omega_{0} P_{t}^{(T)}$

where $P_{t}^{(T)}$ is a pulse function,

$P_{t}^{(T)}= \begin{cases}0 & t \neq T \\ 1 & t=T\end{cases}$

The parameter $\omega_{0}$ measures the change caused by the intervention and is estimated with the ARMA time series components. The estimation procedure provides an estimate of $\omega_{0}$ and a confidence interval for the parameter. The intervention variable $I_{t}$ is expressed as a dummy variable indicating either a specific time prior/ after the election or an approximate shape of the cyclical behavior during the incumbency.

We establish four sets of different political dummy variables $\left(I_{t}\right)$ to analyze the impact of the election on the fiscal deficit as well as the implied contribution on the accumulation of public debt.

Note: For convenience, we denote $P_{t}^{(T)}$ by $P D$ representing the political dummy variable.

The first set consists of sixteen cumulative pre-election and post-election political dummy variables defined as:
PDcum $_{e}=\left\{\begin{array}{l}1-\text { the calendric quarter when elections } \\ \text { take place, Elections Quarter }(E Q) \\ 0-\text { otherwise }\end{array}\right.$

PDcum $_{-i}=\left\{\begin{array}{l}1: \text { for }(i) \text { cumulative } \\ \text { quarters prior to the } E Q, i \in[1 ; 7] \\ 0: \text { otherwise }\end{array}\right.$

PDcum $_{i}=\left\{\begin{array}{l}1: \text { for }(i) \text { cumulative } \\ q \text { quarters after the } E Q, i \in[1 ; 8] \\ 0: \text { otherwise }\end{array}\right.$

These PDs, which are individually incorporated into the specified models, aim to separately capture the election impact toward fiscal deficit before or after the election, throughout the different cumulative periods of time preceding or succeeding the EQ as well as during the EQ. The second set consists of four yearly political dummy variables $\left(P D y_{i}\right)$ defined as:

$P D y_{-1}=\left\{\begin{array}{l}1-\text { from the } E Q \text { up to the } 3^{\text {rd }} \\ \text { quarter before the } E Q \\ 0 \text {-otherwise }\end{array}\right.$

$P D y_{-2}=\left\{\begin{array}{l}1-\text { from the } 4^{\text {th }} \text { up to the } 7^{\text {th }} \\ \text { quarter before the } E Q \\ 0 \text {-otherwise }\end{array}\right.$

$P D y_{1}=\left\{\begin{array}{l}1-\text { from the } 1^{\text {st }} \text { up to the } 4^{\text {th }} \\ \text { quarter after the } E Q \\ 0 \text {-otherwise }\end{array}\right.$

$P D y_{2}=\left\{\begin{array}{l}1-\text { from the } 5^{\text {th }} \text { up to the } 8^{\text {th }} \\ \text { quarter the } E Q \\ 0-\text { otherwise }\end{array}\right.$

These variables allow us to analyze the incumbent behavior during each specific yearly time window before and after elections, while at the same time avoiding the potential problem of the temporal aggregation that is present in annual data (see Streb et al., 2012), as explained in the previous sub-section. The third set includes seven couplets of political dummy variables, which are time-symmetric to elections $\left(P D\right.$ sym $\left._{i}\right)$. Each couplet of these dummy variables covers a symmetric time surrounding elections and is defined as: 


$$
\text { Couplet }(i)=\left\{\begin{array}{l}
\text { PDsym }_{-i}=\left\{\begin{array}{l}
1-\text { for }(i) \text { cummulative quarters } \\
\text { before EQ } \text { including EQ } \\
0-\text { otherwise }
\end{array}\right. \\
P \text { sym }_{i}=\left\{\begin{array}{l}
1-\text { for }(i) \text { cummulative quarters } \\
\text { after } E Q \\
0-\text { otherwise }
\end{array}\right.
\end{array}\right\}
$$

where $i \in[1 ; 7]$. Note: In this case, PDsym indicates the election quarter (EQ).

Both PDs from each couplet are incorporated and estimated simultaneously in the statistical models. The main scope of these variables is to indicate the magnitude of the possible fiscal deficit expansion relative to the contraction in exactly the same time interval surrounding the election, which permits inferring any net effect of PFC on the accumulation of public debt. The fourth set of political dummy variables we design contains twelve $V$-shaped variables. These are certain ordinal variables intended to mimic the possible shape of the political cycle, which may be a significant determinant in the evolution of the fiscal deficit during an incumbent's full electoral tenure. ${ }^{4}$ The empirical technique with these variables was originally used by McCallun (1978) and later by Grier (1987; 1989; 2008), Beck (1987) and Krause (2005). The statistical significance of any of these variables influences the existence of $\mathrm{PBC}$ in the evolution of the interest variable between two consecutive parliamentary elections. Using such variables could also indicate the most likely pattern of the hypothesized somewhat $V$-shaped political cycle. Nevertheless, this technique could only provide statistical evidence that a specific somewhat $V$-shaped variable could Granger-cause fiscal deficit, implying the existence of a political cycle with a pattern similar to the $\mathrm{V}$-shaped variable.

The exact magnitude, form or timing of the cycle is not provided by the empirical technique. We designed four of the $V$-shaped variables to be fully symmetrical relative to respective troughs. They differ among each other with respect to the steepness of the expansion and contraction as well as the trough duration ( $P D$ cycle $_{1}$ to $\left.\mathrm{PDcycle}_{4}\right)$. The next four political $V$-shaped dummy variables model different tendencies toward the expansion phase of the cycle. Variables PDcycle ${ }_{5}$ to PDcycle ${ }_{9}$ model the case in which the expansion of the fiscal deficit occurs before the election (or around the second half of incumbency) and has a greater magnitude and/or lasts longer than the contraction, which occurs after the election (or around the first half of incumbency). Therefore, if statistically significant, the expansion-biased $\mathrm{V}$-shape variables could provide statistical evidence that, in addition to the existence of PBC, the fiscal consolidation that occurs after the election is not enough to fully offset the pre-electoral fiscal expansion, thus contributing to the further accumulation of public debt. While the last four variables, PDcycle ${ }_{10}$ to PDcycle ${ }_{12}$, model the opposite case, an expansion of deficit, which is more than offset by a stronger contraction after the election, and implies an overall reductive effect on public debt stock. Figure 1 shows the specific designed form of each $V$-shaped dummy variable during an incumbent's full tenure (or during the time interval between two consecutive parliamentary elections). Note that some of the PD variables from different sets are identical, such as $\mathrm{PDcum}_{4}$ and $P D y_{1}, P D$ cum $_{e}$ and PDsym ${ }_{-1}$, as well as PDcum ${ }_{i}$ and PDsym $_{i}$ for all (i).

\subsection{Specification and estimation of the statistical models}

In the first stage, we precisely followed the Box-Jenkins methodology (Box \& Jenkins, 1970), specifying the most appropriate ARMA model for the fiscal deficit denominated both in nominal terms and as a ratio of the GDP. ${ }^{5}$ We investigated both time series on the presence of any seasonal pattern as well as on the stationarity. ${ }^{6}$ In the event of a non-stationary time series, we transformed the data into a stationary times series by applying the appropriate transformation approach. We employed an iterative process of identification, estimation and diagnostic checking of several ARMA models until we finally settled on the most plausible model - the one considered the "best" model for each time series. Modeling through ARMA makes it possible to statistically determine whether elections can explain any changes in the fiscal deficit or the natural pattern of the variable and its random error term.

Fiscal deficit denominated both in nominal and percent-to-GDP terms were unit root processes. The first difference in the natural logarithm of the fiscal deficit (DLNNETDEF) as well as the first difference in the fiscal deficit as a ratio of the GDP (DNETDEF_GDP) were stationary processes based on all conventional 

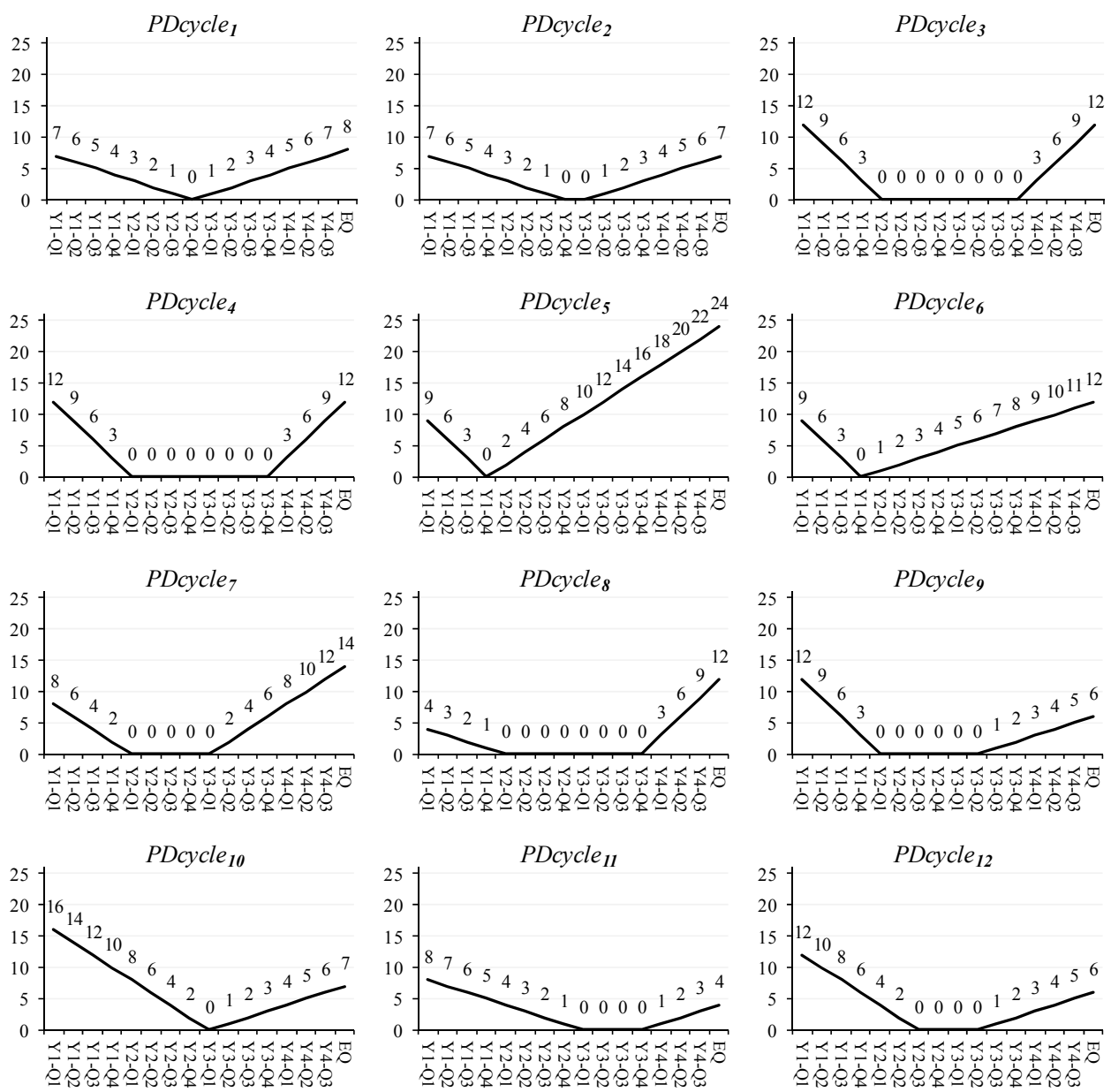

Figure 1. V-Shaped Political Dummy Variables

tests. Therefore, the final variables of interest (dependent variables) subject to our econometric modeling and analysis are as follows:

DLNNETDEF = the first order difference of the natural logarithm of fiscal deficit

DNETDEF_GDP = the first order difference of fiscal deficit as a percentage ratio to GDP After omitting the outlier observations from the respective time series of first order differences, the effective final number of observations used in the empirical analysis was
$51 .^{7}$ Among all competing possible models we estimated and diagnosed, the "best" model for DLNNETDEF was determined to be the ARMA with two autoregressive terms of lag two $A R(2)$ and four $A R(4)$ and two moving average terms of lags one $M A(1)$ and two $M A(2)$. The "best" model for DNETDEF_GDP was an $A R M A$ with a moving average term of lag one $M A(1)$ and an autoregressive term of lag four $A R(4){ }^{8}$

In the second stage, based on the Box-Tiao intervention analysis, we incorporated one defined political 
dummy variable at a time (or in pairs in the case of $P_{\text {Dsym }}$ ) into the "best" tentatively found ARMA model and re-estimated all parameters of each final model. The statistical significance of the political dummy variables, tested using a $t$-test, reveals any possible impact of the elections on the fiscal deficit. ${ }^{9}$ The obtained results are discussed in the following section.

\section{Empirical Results}

The empirical analysis revealed clear evidence of election-related cycles in the fiscal deficit, both in nominal and GDP terms. The estimated coefficients of all types of $P D$ used in the statistical analyses indicated that there is a statistically significant increase in the fiscal deficit during different time-intervals before elections followed by contractions after the elections, thus supporting the hypothesis of opportunistic behavior by incumbents in Hungary. Tables 1 and 2 of this section contain only the most relevant results regarding coefficient estimates for all $P D$ variables used in the analysis, respectively, for the fiscal deficit in nominal terms and the deficit in terms of the GDP, whereas the tables in Appendix A contain the full statistical results for each estimated model.

In the case of a nominal deficit, the parameter estimates for all $P D$ cum $_{-i}$ and $P D$ cum $_{e}$ variables have a positive sign and are statistically significant at a less than $5 \%$ level of significance, while in the event of a deficit denominated as a ratio to GDP, all but $\mathrm{PDcum}_{e}$ are statistically positive at less than $5 \%$, strongly implying an election-related expansionary fiscal policy.

The increase in both measures of the deficit before elections intensifies as election day approaches, as indicated by the increase in the magnitude of several consecutive PDcum $_{-i}$ (PDcum $_{-5}<$ PDcum $_{-4}<$ PDcum $_{-3}$

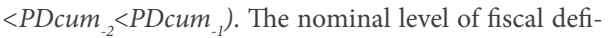
cit spikes by almost $80 \%$ one quarter before the election quarter (EQ) as indicated by $P D c u m_{-1,}$ and almost $70 \%$ in the EQ (PDcum $)$ compared to its natural longterm pattern modeled by the ARMA components. The average nominal expansion of the deficit during other cumulative periods before the EQ ranged from approximately $18 \%$ to $40 \%$ more than its natural pattern, as indicated by estimated coefficients of PDcum to $\mathrm{PDcum}_{-7}$ and was significant at less than $5 \%$.

Fiscal deficit measured as a ratio of the nominal GDP increases by approximately 3.2 percentage points of the GDP one quarter before the EQ (PDcum ${ }_{-1}$ ), while it is approximately 1 to 1.8 percentage points of the GDP higher during different cumulative periods before the EQ (PDcum toPDcum $_{-7}$ ), the vast majority of which are statistically significant at a $1 \%$ level of significance.

Empirical results indicate that this loosening fiscal behavior vanished immediately after elections. Furthermore, statistically significant fiscal consolidation occurs within a cumulative period of three quarters up to two years after the EQ. The coefficients of PDcum and $\mathrm{PDcum}_{2}$ are not significant for either measurement of deficit or for the $\mathrm{PDCum}_{3}$ for the ratio of deficit to the GDP, implying a discontinuation of the expansionary fiscal policy immediately after an election. The PDcum (PDcum $_{4}$ in the case of the deficit to the GDP ratio) to the PDcum $_{8}$ results are significantly negative at a less than $5 \%$ level of significance, indicating a reduction in the fiscal deficit from approximately $22 \%$ to $29 \%$ less than the long-term pattern in nominal terms and approximately 1 percentage point in terms of the GDP.

When we analyze the effects of elections in "yearly time windows" surrounding the event, we can infer that fiscal policy was opportunistically manipulated only during the first yearly time windows before or after elections, while there was no econometrically important alteration of the fiscal deficit in the second yearly time windows. The estimated parameters of $P D y_{-1}$ were significantly positive and those of $P D y_{1}$ were significantly negative at the conventional level of significance for both measurements of the fiscal deficit, while the coefficients of $P D y_{-2}$ and $P D y_{2}$, although with the expected sign, were not statistically significant at conventional levels. When first considered, the nonsignificance of $P D y_{-2}$ and $P D y_{2}$ may seem to contradict the implications derived, respectively, from statisti-

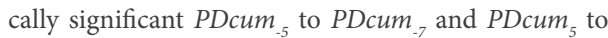
PDcum $_{8}$. Nonetheless, it should be noted that, by definition, these two types of variables capture election effects on the deficit for different periods of time, and therefore, the variables reveal different implications. When we use PDcum variables, we consider the time around the election as a continuum time-interval; therefore, any significant election effects captured by these variables is interpreted as the cumulative effect during that specific continuous time-interval around the election considered as a whole, modeled by each 
Table 1. Election effects on the nominal fiscal deficit (DLNNETDEF)

\begin{tabular}{|c|c|c|c|c|c|c|c|c|}
\hline Variable & Coeff. & Sig. & Variable & Coeff. & Sig. & Variable & Coeff. & Sig. \\
\hline Pdcume ** & 0.689 & 0.025 & $P D y_{-1} * * *$ & 0.255 & 0.001 & PDsym $_{-7}$ & 0.174 & 0.186 \\
\hline PDcum $_{-1}{ }^{* * *}$ & 0.788 & 0.000 & $P D y_{-2}$ & 0.126 & 0.375 & $\mathrm{PDsym}_{7}$ & -0.081 & 0.550 \\
\hline PDcum $_{-2}$ *** & 0.404 & 0.001 & $P D y_{1} * *$ & -0.233 & 0.010 & PDcycle $_{1}$ & 0.023 & 0.321 \\
\hline PDcum $_{-3}$ *** & 0.266 & 0.004 & $P D y_{2}$ & -0.150 & 0.197 & PDcycle $_{2}$ & 0.006 & 0.833 \\
\hline PDcum $_{-4}$ ** & 0.205 & 0.012 & PDsym $_{-1}$ *** & 1.276 & 0.000 & PDcycle $_{3}$ & 0.010 & 0.824 \\
\hline PDcum $_{-5}$ ** & 0.183 & 0.020 & $\operatorname{PDsym}_{1}{ }^{* * *}$ & -0.996 & 0.000 & PDcycle $_{4}$ & 0.003 & 0.824 \\
\hline PDcum $_{-6}{ }^{* *}$ & 0.212 & 0.021 & PDsym $_{-2}$ *** & 0.545 & 0.000 & PDcycle $_{5}{ }^{* * *}$ & 0.016 & 0.001 \\
\hline PDcum $_{-7}$ ** & 0.210 & 0.022 & $\operatorname{PDsym}_{2}{ }^{* * *}$ & -0.331 & 0.003 & PDcycle $_{6}{ }^{* *}$ & 0.027 & 0.018 \\
\hline PDcum $_{1}$ & -0.449 & 0.227 & PDsym $_{-3}{ }^{* * *}$ & 0.329 & 0.002 & PDcycle $_{7}{ }^{*}$ & 0.018 & 0.061 \\
\hline PDcum $_{2}$ & -0.302 & 0.130 & $\operatorname{PDsym}_{3}{ }^{* * *}$ & -0.293 & 0.009 & Pdcycle $_{8}{ }^{* *}$ & 0.027 & 0.046 \\
\hline PDcum $_{3}{ }^{* * *}$ & -0.289 & 0.009 & PDsym $_{-4}$ ** & 0.196 & 0.019 & PDcycle $_{9}$ & -0.009 & 0.650 \\
\hline $\mathrm{PDcum}_{4}{ }^{* *}$ & -0.233 & 0.010 & PDsym $_{4}$ & -0.144 & 0.107 & PDcycle $_{10}$ & -0.016 & 0.170 \\
\hline PDcum $_{5}{ }^{* *}$ & -0.208 & 0.014 & $P$ ssym $_{-5}$ ** & 0.171 & 0.035 & PDcycle $_{11}$ & -0.026 & 0.190 \\
\hline PDcum $_{6}{ }^{* *}$ & -0.227 & 0.016 & PDsym $_{5}$ & -0.122 & 0.169 & PDcycle $_{12}$ & -0.009 & 0.541 \\
\hline PDcum $_{7}$ *** & -0.255 & 0.005 & PDsym $_{-6} *$ & 0.170 & 0.061 & & & \\
\hline PDcum $_{8}{ }^{* * *}$ & -0.258 & 0.002 & PDsym $_{6}$ & -0.103 & 0.283 & & & \\
\hline
\end{tabular}

$\left({ }^{* * *}\right)$ significant at $1 \%$ level $\quad\left({ }^{* *}\right)$ significant at $5 \%$ level $\quad\left({ }^{*}\right)$ significant at $10 \%$ level

Table 2. Election effects on the fiscal deficit to GDP ratio (DNETDEF_GDP)

\begin{tabular}{|c|c|c|c|c|c|c|c|c|}
\hline Variable & Coeff. & Sig. & Variable & Coeff. & Sig. & Variable & Coeff. & Sig. \\
\hline PDcum $_{e}$ & 0.975 & 0.492 & $P D y_{-1} * *$ & 1.010 & 0.018 & $P_{\text {Dsym }}$ & 0.121 & 0.851 \\
\hline PDcum $_{-1}$ ** & 3.179 & 0.014 & $P D y_{-2}$ & 0.574 & 0.199 & PDsym $_{7}$ & -1.030 & 0.134 \\
\hline PDcum $_{-2}$ ** & 1.812 & 0.010 & $P D y_{1} *$ & -0.954 & 0.066 & PDcycle $_{1}$ & 0.062 & 0.417 \\
\hline PDcum $_{-3}$ *** & 1.325 & 0.009 & $P D y_{2}$ & -0.508 & 0.291 & PDcycle $_{2}$ & 0.024 & 0.763 \\
\hline PDcum $_{-4} * *$ & 1.050 & 0.012 & PDsym $_{-1}$ & 2.740 & 0.118 & PDcycle $_{3}$ & 0.051 & 0.691 \\
\hline PDcum $_{-5}$ *** & 0.994 & 0.007 & PDsym $_{1}$ & -2.639 & 0.135 & PDcycle $_{4}$ & 0.017 & 0.691 \\
\hline PDcum $_{-6}{ }^{* * *}$ & 0.975 & 0.005 & PDsym $_{-2}$ ** & 1.896 & 0.012 & PDcycle $_{5}{ }^{* * *}$ & 0.070 & 0.002 \\
\hline PDcum $_{-7}$ *** & 0.991 & 0.003 & $P \operatorname{Dsym}_{2}{ }^{* *}$ & -1.521 & 0.050 & PDcycle $_{6}{ }^{* * *}$ & 0.122 & 0.009 \\
\hline PDcum $_{1}$ & -0.828 & 0.568 & PDsym $_{-3}$ ** & 1.204 & 0.013 & PDcycle $_{7} *$ & 0.066 & 0.081 \\
\hline PDcum $_{2}$ & -0.649 & 0.431 & PDsym $_{3} *$ & -1.025 & 0.054 & Pdcycle $_{8}$ & 0.073 & 0.172 \\
\hline PDcum $_{3}$ & -0.882 & 0.165 & $P_{\text {sym }}^{-4}$ ** & 0.886 & 0.026 & PDcycle $_{9}$ & 0.001 & 0.983 \\
\hline $\mathrm{PDcum}_{4}$ * & -0.967 & 0.061 & $\mathrm{PDsym}_{4}$ * & -0.814 & 0.064 & PDcycle $_{10}$ & -0.065 & 0.136 \\
\hline PDcum $_{5}$ ** & -1.032 & 0.019 & PDsym $_{-5}$ * & 0.665 & 0.078 & PDcycle $_{11}$ & -0.120 & 0.108 \\
\hline PDcum $_{6}{ }^{* * *}$ & -1.095 & 0.004 & PDsym $_{5}$ * & -0.745 & 0.077 & PDcycle $_{12}$ & -0.037 & 0.501 \\
\hline $\operatorname{PDcum}_{7}{ }^{* * *}$ & -1.142 & 0.001 & PDsym $_{-6}$ & 0.529 & 0.198 & & & \\
\hline $\operatorname{PDcum}_{8}{ }^{* * *}$ & -1.059 & 0.001 & PDsym $_{6}$ & -0.730 & 0.108 & & & \\
\hline
\end{tabular}

$\left({ }^{* *}\right)$ significant at $1 \%$ level $\quad\left({ }^{* *}\right)$ significant at $5 \%$ level $\quad(*)$ significant at $10 \%$ level 
specific PDcum, and relative to the rest of the time subject to our analysis With respect to the $P D y$ variables, possible election effects are tested and interpreted only for a separate time window of four quarters (one year) somewhere around the election, relative to the entire time span considered in the study.

In addition to enhancing the implications given thus far, the analysis based on the other two sets of defined political dummies, PDsym and PDcycle, provides some inconclusive indications for another hypothetical characteristic of PFCs in Hungary, that of proactive public debt accumulation. Almost all couplets of PDsym used in the analyses indicate that the fiscal expansion occurring before elections is somewhat higher than that of the post-election fiscal consolidation for each symmetrical time interval. More specifically, the increase in the fiscal deficit during different cumulative periods of time before elections, as captured by the significantly positive coefficients of PDsym (-i) $_{\text {, }}$ is not fully offset by deficit contractions during the symmetrical periods of time after the elections, as captured by the significantly negative (or insignificant in some cases) coefficients of PDsym $(i)$. This was valid for both measurements of the fiscal deficit, except for Couplet ${ }_{(5)}$ in the case of the deficit to the GDP ratio, which showed slightly stronger consolidation after elections than the respective preceding expansion and was significant at $10 \%$. Based only on an intuitive calculation of the PFCs' net effects, the expansion during different time-intervals before the election ranged from approximately 3.6 to 28 percentage points higher than the respective contraction afterwards, in the case of the nominal deficit. ${ }^{10}$ In the case of the deficit to GDP ratio, the incline toward preelectoral fiscal expansion ranged from approximately 0.07 to 0.37 percentage points of the GDP, except for the PDsym $m_{-5}$ and PDsym ${ }_{5}$, where the difference between the two favored post-election contractions by 0.08 percentage point of the GDP. Nevertheless, these results from the PDsym variables could only be considered indicative and were not statistically conclusive. Based on the results of the Walt test, we could not reject the null hypothesis that the sum of the estimated parameters for each Couplet $($ i) is equal to zero for both measurements of the GDP. ${ }^{11}$ This means that the empirical evidence from this sample of observations that are subject to this particular analysis is not sufficient to assert with a conventional degree of statistical confidence that fis- cal expansions before elections are significantly higher than their respective time-symmetric contractions after elections. Therefore, by implication, we cannot conclude with statistical certainty that evident PFCs in Hungary also have an impact on the accumulation of public debt. However, the above-mentioned differences in the estimated coefficients are indicative of the hypothesized PFCs' effects on the accumulation of debt, a finding that is also supported by the results obtained when using PDcycle $_{i}$ dummy variables. Among all three sub-sets of these variables - the first sub-set with dummy variables models a symmetrical fiscal cycle along a full incumbency, the second models a stronger expansion versus contraction phase of the fiscal cycle and the third models a stronger contraction phase only the second type of PDcycle variables were statistically significant at conventional levels. With respect to the nominal deficit, PDcycle ${ }_{5}$ was significant at the $1 \%$ level, $P D c y c l e_{6}$ and PDcycle ${ }_{8}$ were significant at the $5 \%$ level, and PDcycle ${ }_{7}$ was significant at the $10 \%$ level. While in the case of the deficit denominated as a percentage of the GDP, PDcycle ${ }_{5}$ and PDcycle $_{6}$ were significant at the $1 \%$ level, the PDcycle ${ }_{7}$ at the $10 \%$ level and the PDcycle ${ }_{8}$ was not significant. Based on the AIC and $B I C$ criteria, the best models for both measurements of fiscal deficit were those with PDcycle 5 variables, as they entailed the closest resemblance to true fiscal cycle among all PDcycle variables employed in the study. It should be noted that among all variables, as designed, PDcycle $_{5}$ is the one that emphasizes the greatest tendency toward the expansion versus contraction phase of the assumed fiscal cycle, either in the magnitude or time span. Again, these results with PDcycle variables are only indicative and do not infer statistically significant conclusions with regards to the hypothesized PFC effects on public debt. Further empirical analysis is needed to reach such conclusions.

\section{Conclusions}

In our search for political fiscal (budget) cycles in Hungary, we found clear evidence of fiscal expansion before elections and contractions after elections. Furthermore, the fiscal deficit in both nominal and GDP terms increased significantly during different cumulative time-intervals before elections, and the increase became incremental as election day approached. The increase in the deficit was not only statistically signifi- 
cant but was substantial in size as the deficit increase ranged from approximately $18 \%$ above its natural long-term pattern in the cumulative terms two years before elections to approximately $70 \%$ closer to the time of the election. Fiscal expansion ceased immediately after elections, and fiscal consolidation took place at the range of $22 \%$ to $29 \%$ during four to eight cumulative quarters after the elections, completing the next phase of PFCs in Hungary. When the elections' effects on the fiscal deficit were considered in yearly timewindows around elections, we found those effects to be econometrically important only in the first yearly time-windows before and after the event.

In addition to the presence of a PFC in Hungary and consistent with the common knowledge in the field of political business cycles, we also found some evidence that such politically motivated fiscal cycles may contribute to the accumulation of public debt stock. The fiscal deficit increases prior to elections and is followed by contractions after elections, a phenomenon that leans toward the expansionary side. Nevertheless, we could not conclusively confirm with conventional statistical certainty that existing PFCs in Hungary are also an underlying factor causing the accumulation of public debt in Hungary. Further analysis, however, could reveal a statistically conclusive answer to this hypothesis.

These empirical findings support the hypothesis regarding the existence of politically motivated fiscal policy cycles in Hungary. We found indications, although not statistically significant, that PFCs may contribute to the accumulation of public debt. Therefore, the existence of a PFC can be inefficient for the economy of Hungary in medium- and long-term time-horizons.

\section{References}

Akhmedov, A., Zhuravskaya, E. (2004). Opportunistic political cycles: test in a young democracy setting. The Quarterly Journal of Economics, 119 (4), 1301-1338.

Alesina, A. (1987). Macroeconomic policy in a twoparty system as a repeated game. The Quarterly Journal of Economics, 102 (3), 651-678.

Alesina, A., Sachs, J. (1988). Political parties and the business cycle in the United States, 1948-1984. Journal of Money, Credit and Banking, 20 (1), 63-82.

Alesina, A., Rosenthal, H. (1995). Partisan politics, divided government, and the economy. Cambridge, UK: Cambridge University Press.
Alesina, A., Roubini, N. (1992). Political cycles in OECD economies. Review of Economic Studies, 59 (4), 663-688.

Alesina, A., Roubini, N., \& Cohen G. D. (1997). Political cycles and the macroeconomy. Cambridge, MA: The MIT Press.

Alt, J. E., \& Lassen, D. D. (2006).Transparency, political polarization, and political budget cycles in OECD countries. American Journal of Political Science, 50 (3), 530-550.

Ames, B. (1987). Political survival: Politicians and public policy in Latin America (Vol. 12). Berkeley, CA: University of California Press.

Asutay, M. (2004, April). Searching for opportunistic political business cycles in Turkey. Paper presented at Annual Conference of the European Public Choice Society, Berlin.

BBC (2012).Hungary aid frozen by EU over budget deficit. Available on http://www.bbc.co.uk/news/ business-17357626, accessed in March 2013.

Beck, N. (1987). Elections and the FED: Is there a political monetary cycle? American Journal of Political Science, 31 (1), 194-216.

Block, S. A. (2002). Political business cycles, democratization, and economic reform: the case of Africa. Journal of Development Economics, 67 (1), 205-228.

Box, G. E. P., Jenkins, G. M. (1970).Time series analysis, forecasting and control. San Francisco, CA: Holden-Day Inc.

Box, G. E. P., Tiao, G. C. (1975). Intervention analysis with applications to economic and environmental problems. Journal of American Statistical Association, 70 (349), 70-79.

Brender, A., Drazen A. (2005). Political budget cycles in new versus established democracies. Journal of Monetary Economics, 52 (7), 1271-1295.

Cukierman, A., Meltzer, A. H. (1986). A positive theory of discretionary policy, the costs of democratic government, and the benefits of a constitution. Economic Inquiry, 24 (3), 367-388.

Enders, W. (2004). Applied econometric time series ( $2^{\text {nd }}$ ed.). New York, NY: John Wiley \& Sons.

EUROSTAT (2012). Database. Available at: http:// appsso.eurostat.ec.europa.eu/nui/setupModifyTableLayout.do

Galli, E., Rossi, S. P. S. (2002). Political budget cycles: 
the case of the western German lander. Public Choice, 110 (3-4), 283-303.

Grier, K. B. (1987). Presidential election and Federal Reserve Policy: An empirical test. Southern Economic Journal, 54 (2), 475-486.

Grier, K. B. (1989). On the existence of a political monetary cycle. American Journal of Political Science, 33 (2), 376-389.

Grier, K. B. (2008). US presidential elections and real GDP growth, 1961-2004. Public Choice, 135 (34), 337-352.

Haggard, S., Kaufman, R. R., \& Shugart, M. (2001). Politics, Institutions, and Macroeconomic Adjustment: Hungarian Fiscal Policy Making in Comparative Perspective. In J. Kornai, S. Haggard, R. R. Kaufman, R. (Eds.), Reforming the State Fiscal and Welfare Reform in Post-Socialist Countries (pp. 75110). Cambridge, UK: Cambridge University Press.

Hallenberg, M., de Souza, L. V., \& Clark, W. R. (2002). Political business cycles in EU accession countries. European Union Politics, 3 (2), 231-250.

Hibbs, D. A. (1977). Political parties and macroeconomic policy. American Political Science Review, 71(4), 1467-1487.

Hibbs, D. A. (1987). The American Political Economy: Macroeconomics and Electoral Politics. Cambridge, MA: Harvard University Press.

Imami, D., Lami, E. (2006). Searching for political business cycles in Albania. Periodica Politechnica, 14 (2), 53-69.

Krause, G. A. (2005). Electoral incentives, political business cycles and macroeconomic performance: empirical evidence from post-war US personal income growth. British Journal of Political Science, 35 (1), 77-101.

McCallum, B. (1978). The political business cycle: an empirical test. Southern Economic Journal, 44 (3), 504-515.

Nordhaus, W. D. (1975). The political business cycle. Review of Economic Studies, 42 (2), 169-190.

Persson, T., Tabellini, G. (1990). Macroeconomic policy, credibility and politics. Chur Switzerland: Harwood Academic Publishers.

Persson, T., Tabellini, G. (2003). The economic effect of constitutions. Cambridge, MA: MIT Press.

Rose, S. (2006). Do fiscal rules dampen fiscal cycle?. Public Choice, 128 (3-4), 407-431.
Roggof, K., Sibert, A. (1988). Elections and macroeconomic policy cycles. Review of Economic Studies, 55 (1), 1-16.

Schuknecht, L. (2000). Fiscal policy cycles and public expenditure in developing countries. Public Choice, 102 (1-2), 113-128

Shi, M., Svensson, J. (2002).Conditional Political Budget Cycles (Discussion Paper No. 3352). Centre for Economic Policy Research.

Shi, M., Svensson J. (2003).Political budget cycles: a review of recent developments. Nordic Journal of Political Economy, 29 (1), 67-76.

Shi, M., Svensson, J. (2006). Political budget cycles: do they differ across countries and why? Journal of Public Economics, 90 (8-9), 1367-1389.

Streb, M. J., Lema, D., Garofalo, P. (2012). Temporal aggregation in political budget cycles. Journal of the Latin American and Caribbean Economic Association, 13 (1), 39-78.

Streb, M. J., Lema, D., Torrens, G. (2009). Checks and balances on political budget cycles: Cross-country evidence. Kyklos, 62 (3), 426-447.

Than, K., Szakacs, G. (2012, December 7). ECB warns Hungary again over central bank independence. Retrieved from http://www.reuters.com/article/2012/12/07/us-ecb-draghi-hungary-idUSBRE8B60EG20121207

\section{Endnotes}

1 In their book "Political Cycles and Macroeconomy", Alesina, Roubini and Cohen (1997) provide a comprehensive review of the main theoretical approaches on the issue of $P B C$.

2 Nordhaus (1975) assumes that governments can control the level of unemployment by choosing the appropriate mix of economic policy (monetary and/or fiscal policy).

3 Net lending (+)/net borrowing(-) of the general government is the difference between total revenue and total expenditures of the general government, which is generally referred to as the overall fiscal balance (fiscal surplus or deficit) of the general government. The data used in this study were downloaded from the public source EUROSTAT, on November 2012 (http://appsso.eurostat.ec.europa.eu/nui/setupModifyTableLayout.do).

4 In Hungary, a full incumbency is 16 quarters (4 years) 
5 Enders (2004) provides a practical introduction to BJ methodology and intervention analysis.

6 There was no persistent seasonality in either of the two series. The inclusion of the AR(4) term in both tentatively found models accounted for slight signs of seasonality in the autocorrelation function of lag four. The augmented Dickey-Fuller test, PhilipsPerron test and Kwiatkowski-Phillips-Schmidt-Shin test were employed to assess the stationarity of each time series as well as the autocorrelation and partial autocorrelation functions plots.

7 Due to the reasons explained in section 2.1, observations omitted from the analysis are 2011-Q1 and 2011-Q2. Omission was performed by employing two specific dummy variables representing these observations.

8 The selection between competing ARMA models fitting each time series was based on three formal criteria, the Akaike Information Criterion (AIC), Bayesian Information Criterion (BIC) and Hannan-Quinn Information Criterion (HQC). We did not encounter any case of conflicting selection guidance among these criteria. Several diagnostic formal tests and judgment means were used throughout the Box-Jenkins iterative procedure to determine the "best" ARMA model, such as the Durbin-Watson test, F-test, t-test, ACF and PACF plots, Jarque-Bera test, Q-test and residuals distribution plots.

9 Empirical results remained generally robust when other competing, "second-best" ARMA models were used.

10 Calculated as the sum of PDsym $m_{-i}$ and PDsym when $_{i}$ both were statistically significant or just the magni-

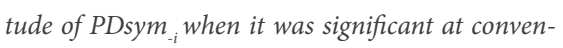
tional levels.

11 ull hypothesis: Coefficient of PDsym ${ }_{(-i)}+$ Coefficient of PDsym $_{(i)}=0 ; i=(1,2, \ldots, 7)$

\section{Acknowledgements}




\section{APPENDIX A}

TABLE A1

Nominal Fiscal Deficit (DLNNETDEF) - with "PDcum" variables (before Election)

ARMA model: $\quad$ DLNNETDEF $=0.015+0.210^{*} D U M \_2011 Q 1+0.425^{*} D U M \_2011 Q 2+[A R(2)=-1.154, A R(4)=-0.279, M A(1)=-0.218, M A(2)=0.938]$

\begin{tabular}{|c|c|c|c|c|c|c|c|c|c|c|c|c|c|c|c|c|}
\hline \multirow{2}{*}{$\begin{array}{l}\text { Estimated model } \\
\text { Explanatory variables }\end{array}$} & \multicolumn{2}{|c|}{ Model 1} & \multicolumn{2}{|c|}{ Model 2} & \multicolumn{2}{|c|}{ Model 3} & \multicolumn{2}{|c|}{ Model 4} & \multicolumn{2}{|c|}{ Model 5} & \multicolumn{2}{|c|}{ Model 6} & \multicolumn{2}{|c|}{ Model 7} & \multicolumn{2}{|c|}{ Model 8} \\
\hline & Coeff. & Sig. & Coeff. & Sig. & Coeff. & Sig. & Coeff. & Sig. & Coeff. & Sig. & Coeff. & Sig. & Coeff. & Sig. & Coeff. & Sig. \\
\hline $\mathrm{C}$ & -0.043 & 0.422 & -0.043 & 0.314 & -0.041 & 0.313 & -0.037 & 0.357 & -0.036 & 0.384 & -0.041 & 0.347 & -0.068 & 0.195 & -0.081 & 0.156 \\
\hline DUM_2011Q1 & -0.124 & 0.818 & 0.293 & 0.482 & 0.317 & 0.457 & 0.214 & 0.629 & 0.071 & 0.876 & -0.057 & 0.899 & -0.141 & 0.785 & -0.116 & 0.823 \\
\hline DUM_2011Q2 & 1.240 & 0.028 & 0.585 & 0.154 & 0.397 & 0.344 & 0.380 & 0.385 & 0.463 & 0.302 & 0.596 & 0.186 & 0.901 & 0.093 & 0.926 & 0.084 \\
\hline $\operatorname{AR}(2)$ & -1.172 & 0.000 & -0.739 & 0.000 & -0.795 & 0.000 & -0.857 & 0.000 & -0.907 & 0.000 & -0.934 & 0.000 & -1.002 & 0.000 & -0.983 & 0.000 \\
\hline $\operatorname{AR}(4)$ & -0.373 & 0.003 & -0.067 & 0.596 & -0.166 & 0.184 & -0.248 & 0.047 & -0.294 & 0.021 & -0.311 & 0.017 & -0.290 & 0.075 & -0.262 & 0.115 \\
\hline $\mathrm{MA}(1)$ & -0.483 & 0.000 & -1.014 & 0.000 & -1.023 & 0.000 & -1.024 & 0.000 & -1.016 & 0.000 & -1.003 & 0.000 & -0.659 & 0.000 & -0.656 & 0.000 \\
\hline $\operatorname{MA}(2)$ & 0.934 & 0.000 & 0.940 & 0.000 & 0.938 & 0.000 & 0.936 & 0.000 & 0.933 & 0.000 & 0.931 & 0.000 & 0.688 & 0.000 & 0.682 & 0.000 \\
\hline Pdcume & 0.6894 & 0.025 & & & & & & & & & & & & & & \\
\hline PDcum $_{1}$ & & & 0.788 & 0.000 & & & & & & & & & & & & \\
\hline PDcum $_{2}$ & & & & & 0.404 & 0.001 & & & & & & & & & & \\
\hline PDcum $_{3}$ & & & & & & & 0.266 & 0.004 & & & & & & & & \\
\hline PDcum $_{4}$ & & & & & & & & & 0.205 & 0.012 & & & & & & \\
\hline PDcum $_{5}$ & & & & & & & & & & & 0.183 & 0.020 & & & & \\
\hline PDcum $_{6}$ & & & & & & & & & & & & & 0.212 & 0.021 & & \\
\hline PDcum $_{7}$ & & & & & & & & & & & & & & & 0.210 & 0.022 \\
\hline \multicolumn{17}{|c|}{ Diagnostic tests } \\
\hline R-squared & & 0.632 & & 0.680 & & 0.683 & & 0.665 & & 0.648 & & 0.643 & & 0.640 & & 0.641 \\
\hline Adjusted R-squared & & 0.569 & & 0.626 & & 0.629 & & 0.607 & & 0.588 & & 0.582 & & 0.579 & & 0.579 \\
\hline S.E. of regression & & 0.582 & & 0.542 & & 0.540 & & 0.555 & & 0.569 & & 0.573 & & 0.575 & & 0.575 \\
\hline Sum squared resid & & 13.874 & & 12.063 & & 11.950 & & 12.651 & & 13.264 & & 13.466 & & 13.574 & & 13.552 \\
\hline Log likelihood & & -38.615 & & -35.187 & & -34.956 & & -36.353 & & -37.511 & & -37.883 & & -38.077 & & -38.038 \\
\hline F-statistic & & 10.068 & & 12.459 & & 12.632 & & 11.608 & & 10.801 & & 10.550 & & 10.421 & & 10.447 \\
\hline Prob(F-statistic) & & 0.000 & & 0.000 & & 0.000 & & 0.000 & & 0.000 & & 0.000 & & 0.000 & & 0.000 \\
\hline Mean dependent var & & 0.013 & & 0.013 & & 0.013 & & 0.013 & & 0.013 & & 0.013 & & 0.013 & & 0.013 \\
\hline S.D. dependent var & & 0.887 & & 0.887 & & 0.887 & & 0.887 & & 0.887 & & 0.887 & & 0.887 & & 0.887 \\
\hline Akaike info criterion & & 1.903 & & 1.763 & & 1.753 & & 1.810 & & 1.858 & & 1.873 & & 1.881 & & 1.879 \\
\hline Schwarz criterion & & 2.212 & & 2.072 & & 2.062 & & 2.119 & & 2.166 & & 2.182 & & 2.190 & & 2.188 \\
\hline Hannan-Quinn criter. & & 2.020 & & 1.880 & & 1.870 & & 1.928 & & 1.975 & & 1.990 & & 1.998 & & 1.996 \\
\hline Durbin-Watson stat & & 1.928 & & 1.436 & & 1.439 & & 1.467 & & 1.469 & & 1.467 & & 1.876 & & 1.902 \\
\hline
\end{tabular}


TABLE A2

Nominal Fiscal Deficit (DLNNETDEF) - with "PDcum" variables (after Election)

\begin{tabular}{|c|c|c|c|c|c|c|c|c|c|c|c|c|c|c|c|c|}
\hline \multirow{2}{*}{$\begin{array}{l}\text { Estimated model } \\
\text { Explanatory variables }\end{array}$} & \multicolumn{2}{|c|}{ Model 9} & \multicolumn{2}{|c|}{ Model 10} & \multicolumn{2}{|c|}{ Model 11} & \multicolumn{2}{|c|}{ Model 12} & \multicolumn{2}{|c|}{ Model 13} & \multicolumn{2}{|c|}{ Model 14} & \multicolumn{2}{|c|}{ Model 15} & \multicolumn{2}{|c|}{ Model 16} \\
\hline & Coeff. & Sig. & Coeff. & Sig. & Coeff. & Sig. & Coeff. & Sig. & Coeff. & Sig. & Coeff. & Sig. & Coeff. & Sig. & Coeff. & Sig. \\
\hline $\mathrm{C}$ & 0.043 & 0.521 & 0.047 & 0.358 & 0.062 & 0.154 & 0.064 & 0.121 & 0.074 & 0.073 & 0.091 & 0.059 & 0.118 & 0.023 & 0.141 & 0.007 \\
\hline DUM_2011Q1 & 0.277 & 0.641 & -0.061 & 0.915 & 0.454 & 0.338 & 0.435 & 0.379 & 0.343 & 0.497 & 0.120 & 0.818 & 0.014 & 0.978 & -0.121 & 0.791 \\
\hline DUM_2011Q2 & 0.334 & 0.575 & 0.769 & 0.179 & 0.320 & 0.486 & 0.456 & 0.322 & 0.556 & 0.228 & 0.942 & 0.076 & 1.041 & 0.046 & 0.982 & 0.047 \\
\hline $\mathrm{AR}(2)$ & -1.145 & 0.000 & -0.897 & 0.000 & -0.815 & 0.000 & -0.895 & 0.000 & -1.009 & 0.000 & -0.951 & 0.000 & -0.984 & 0.000 & -1.016 & 0.000 \\
\hline $\mathrm{AR}(4)$ & -0.264 & 0.059 & -0.153 & 0.372 & -0.136 & 0.370 & -0.219 & 0.128 & -0.330 & 0.029 & -0.212 & 0.212 & -0.237 & 0.163 & -0.341 & 0.022 \\
\hline $\mathrm{MA}(1)$ & -0.215 & 0.000 & -0.623 & 0.000 & -1.005 & 0.000 & -1.004 & 0.000 & -0.982 & 0.000 & -0.701 & 0.000 & -0.683 & 0.000 & -0.897 & 0.000 \\
\hline $\mathrm{MA}(2)$ & 0.936 & 0.000 & 0.692 & 0.000 & 0.931 & 0.000 & 0.926 & 0.000 & 0.919 & 0.000 & 0.627 & 0.000 & 0.671 & 0.000 & 0.900 & 0.000 \\
\hline PDcum $_{1}$ & -0.4489 & 0.227 & & & & & & & & & & & & & & \\
\hline PDcum $_{2}$ & & & -0.302 & 0.130 & & & & & & & & & & & & \\
\hline PDcum $_{3}$ & & & & & -0.289 & 0.009 & & & & & & & & & & \\
\hline PDcumy & & & & & & & -0.233 & 0.010 & & & & & & & & \\
\hline PDcum $_{5}$ & & & & & & & & & -0.208 & 0.014 & & & & & & \\
\hline PDcum $_{6}$ & & & & & & & & & & & -0.227 & 0.016 & & & & \\
\hline $\mathrm{PDcum}_{7}$ & & & & & & & & & & & & & -0.255 & 0.005 & & \\
\hline PDcum $_{8}$ & & & & & & & & & & & & & & & -0.258 & 0.002 \\
\hline \multicolumn{17}{|c|}{ Diagnostic tests } \\
\hline R-squared & & 0.623 & & 0.616 & & 0.654 & & 0.650 & & 0.644 & & 0.637 & & 0.659 & & 0.678 \\
\hline Adjusted R-squared & & 0.558 & & 0.550 & & 0.595 & & 0.590 & & 0.583 & & 0.576 & & 0.601 & & 0.624 \\
\hline S.E. of regression & & 0.589 & & 0.594 & & 0.564 & & 0.568 & & 0.573 & & 0.578 & & 0.560 & & 0.544 \\
\hline Sum squared resid & & 14.234 & & 14.489 & & 13.039 & & 13.222 & & 13.446 & & 13.675 & & 12.846 & & 12.131 \\
\hline Log likelihood & & -39.242 & & -39.676 & & -37.093 & & -37.434 & & -37.846 & & -38.260 & & -36.728 & & -35.324 \\
\hline F-statistic & & 9.665 & & 9.393 & & 11.088 & & 10.854 & & 10.575 & & 10.300 & & 11.342 & & 12.357 \\
\hline Prob(F-statistic) & & 0.000 & & 0.000 & & 0.000 & & 0.000 & & 0.000 & & 0.000 & & 0.000 & & 0.000 \\
\hline Mean dependent var & & 0.013 & & 0.013 & & 0.013 & & 0.013 & & 0.013 & & 0.013 & & 0.013 & & 0.013 \\
\hline S.D. dependent var & & 0.887 & & 0.887 & & 0.887 & & 0.887 & & 0.887 & & 0.887 & & 0.887 & & 0.887 \\
\hline Akaike info criterion & & 1.928 & & 1.946 & & 1.841 & & 1.854 & & 1.871 & & 1.888 & & 1.826 & & 1.768 \\
\hline Schwarz criterion & & 2.237 & & 2.255 & & 2.149 & & 2.163 & & 2.180 & & 2.197 & & 2.135 & & 2.077 \\
\hline Hannan-Quinn criter. & & 2.045 & & 2.063 & & 1.958 & & 1.972 & & 1.988 & & 2.005 & & 1.943 & & 1.886 \\
\hline Durbin-Watson stat & & 2.292 & & 1.651 & & 1.300 & & 1.356 & & 1.439 & & 1.761 & & 1.825 & & 1.686 \\
\hline
\end{tabular}


TABLE A3

Nominal Fiscal Deficit (DLNNETDEF) - with "PDy" variables

ARMA model: $D L N N E T D E F=0.015+0.210^{*} D U M \_2011 Q 1+0.425 * D U M \_2011 Q 2+$ $[A R(2)=-1.154, A R(4)=-0.279, M A(1)=-0.218, M A(2)=0.938]$

\begin{tabular}{|c|c|c|c|c|c|c|c|c|}
\hline \multirow{2}{*}{$\frac{\text { Estimated model }}{\text { Explanatory variables }}$} & \multicolumn{2}{|c|}{ Model 17} & \multicolumn{2}{|c|}{ Model 18} & \multicolumn{2}{|c|}{ Model 19} & \multicolumn{2}{|c|}{ Model 20} \\
\hline & Coeff. & Sig. & Coeff. & Sig. & Coeff. & Sig. & Coeff. & Sig. \\
\hline $\mathrm{C}$ & -0.036 & 0.384 & -0.031 & 0.680 & 0.064 & 0.121 & 0.047 & 0.367 \\
\hline DUM_2011Q1 & 0.071 & 0.876 & 0.286 & 0.636 & 0.429 & 0.389 & -0.375 & 0.506 \\
\hline DUM_2011Q2 & 0.463 & 0.302 & 0.500 & 0.407 & 0.460 & 0.320 & 0.907 & 0.114 \\
\hline $\mathrm{AR}(2)$ & -0.907 & 0.000 & -1.142 & 0.000 & -0.900 & 0.000 & -0.955 & 0.000 \\
\hline $\operatorname{AR}(4)$ & -0.294 & 0.021 & -0.267 & 0.053 & -0.222 & 0.127 & -0.227 & 0.183 \\
\hline $\mathrm{MA}(1)$ & -1.016 & 0.000 & -0.220 & 0.000 & -1.001 & 0.000 & -0.566 & 0.000 \\
\hline MA(2) & 0.933 & 0.000 & 0.938 & 0.000 & 0.925 & 0.000 & 0.663 & 0.000 \\
\hline $\mathrm{PDy}_{-1}$ & 0.2048 & 0.012 & & & & & & \\
\hline $\mathrm{PDy}_{-2}$ & & & 0.178 & 0.280 & & & & \\
\hline $\mathrm{PDy}_{1}$ & & & & & -0.233 & 0.010 & & \\
\hline $\mathrm{PDy}_{2}$ & & & & & & & -0.150 & 0.197 \\
\hline \multicolumn{9}{|c|}{ Diagnostic tests } \\
\hline R-squared & & 0.648 & & 0.620 & & 0.650 & & 0.608 \\
\hline Adjusted R-squared & & 0.588 & & 0.555 & & 0.590 & & 0.541 \\
\hline S.E. of regression & & 0.569 & & 0.592 & & 0.568 & & 0.600 \\
\hline Sum squared resid & & 13.264 & & 14.353 & & 13.218 & & 14.781 \\
\hline Log likelihood & & -37.511 & & -39.445 & & -37.427 & & -40.166 \\
\hline F-statistic & & 10.801 & & 9.537 & & 10.859 & & 9.091 \\
\hline Prob(F-statistic) & & 0.000 & & 0.000 & & 0.000 & & 0.000 \\
\hline Mean dependent var & & 0.013 & & 0.013 & & 0.013 & & 0.013 \\
\hline S.D. dependent var & & 0.887 & & 0.887 & & 0.887 & & 0.887 \\
\hline Akaike info criterion & & 1.858 & & 1.937 & & 1.854 & & 1.966 \\
\hline Schwarz criterion & & 2.166 & & 2.245 & & 2.163 & & 2.275 \\
\hline Hannan-Quinn criter. & & 1.975 & & 2.054 & & 1.971 & & 2.083 \\
\hline Durbin-Watson stat & & 1.469 & & 2.349 & & 1.359 & & 1.896 \\
\hline
\end{tabular}




\section{TABLE A4}

Nominal Fiscal Deficit (DLNNETDEF) - with "PDsym" variables

ARMA model: $D L N N E T D E F=0.015+0.210^{*} D U M_{-} 2011 Q 1+0.425^{*} D U M_{-} 2011 Q 2+[A R(2)=-1.154, A R(4)=-0.279, M A(1)=-0.218$, $M A(2)=0.938]$

\begin{tabular}{|c|c|c|c|c|c|c|c|c|c|c|c|c|c|c|}
\hline \multirow{2}{*}{$\begin{array}{l}\text { Estimated model } \\
\text { Explanatory variables }\end{array}$} & \multicolumn{2}{|c|}{ Model 21} & \multicolumn{2}{|c|}{ Model 22} & \multicolumn{2}{|c|}{ Model 23} & \multicolumn{2}{|c|}{ Model 24} & \multicolumn{2}{|c|}{ Model 25} & \multicolumn{2}{|c|}{ Model 26} & \multicolumn{2}{|c|}{ Model 27} \\
\hline & Coeff. & Sig. & Coeff. & Sig. & Coeff. & Sig. & Coeff. & Sig. & Coeff. & Sig. & Coeff. & Sig. & Coeff. & Sig. \\
\hline $\mathrm{C}$ & -0.022 & 0.653 & -0.029 & 0.556 & -0.004 & 0.930 & -0.005 & 0.919 & -0.006 & 0.907 & -0.015 & 0.825 & -0.028 & 0.807 \\
\hline DUM_2011Q1 & 0.073 & 0.875 & 0.217 & 0.634 & 0.241 & 0.632 & 0.459 & 0.321 & 0.348 & 0.461 & 0.156 & 0.730 & -0.036 & 0.935 \\
\hline DUM_2011Q2 & 1.003 & 0.033 & 0.865 & 0.050 & 0.774 & 0.093 & 0.429 & 0.318 & 0.513 & 0.240 & 0.685 & 0.115 & 0.869 & 0.052 \\
\hline $\operatorname{AR}(2)$ & -0.787 & 0.000 & -0.819 & 0.000 & -0.885 & 0.000 & -0.887 & 0.000 & -0.943 & 0.000 & -0.940 & 0.000 & -0.983 & 0.000 \\
\hline $\mathrm{AR}(4)$ & -0.015 & 0.910 & -0.042 & 0.757 & -0.149 & 0.286 & -0.219 & 0.108 & -0.288 & 0.035 & -0.289 & 0.034 & -0.317 & 0.034 \\
\hline $\mathrm{MA}(1)$ & -0.805 & 0.000 & -0.806 & 0.000 & -0.809 & 0.000 & -1.011 & 0.000 & -1.015 & 0.000 & -1.013 & 0.000 & -0.972 & 0.000 \\
\hline $\mathrm{MA}(2)$ & 0.940 & 0.000 & 0.937 & 0.000 & 0.920 & 0.000 & 0.929 & 0.000 & 0.928 & 0.000 & 0.932 & 0.000 & 0.922 & 0.000 \\
\hline PDsym $_{1}$ & 1.2756 & 0.000 & & & & & & & & & & & & \\
\hline PDsym $_{1}$ & -0.996 & 0.000 & & & & & & & & & & & & \\
\hline PDsym $_{2}$ & & & 0.545 & 0.000 & & & & & & & & & & \\
\hline $\mathrm{PDsym}_{2}$ & & & -0.331 & 0.003 & & & & & & & & & & \\
\hline $\operatorname{PDsym}_{3}$ & & & & & 0.329 & 0.002 & & & & & & & & \\
\hline PDsym $_{3}$ & & & & & -0.293 & 0.009 & & & & & & & & \\
\hline $\mathrm{PDsym}_{4}$ & & & & & & & 0.196 & 0.019 & & & & & & \\
\hline $\mathrm{PDsym}_{4}$ & & & & & & & -0.144 & 0.107 & & & & & & \\
\hline PDsym $_{-5}$ & & & & & & & & & 0.171 & 0.035 & & & & \\
\hline PDsym $_{5}$ & & & & & & & & & -0.122 & 0.169 & & & & \\
\hline PDsym_6 $_{6}$ & & & & & & & & & & & 0.170 & 0.061 & & \\
\hline PDsym $_{6}$ & & & & & & & & & & & -0.103 & 0.283 & & \\
\hline $\mathrm{PDsym}_{-7}$ & & & & & & & & & & & & & 0.174 & 0.186 \\
\hline $\mathrm{PDsym}_{7}$ & & & & & & & & & & & & & -0.081 & 0.550 \\
\hline \multicolumn{15}{|c|}{ Diagnostic tests } \\
\hline R-squared & & 0.729 & & 0.748 & & 0.717 & & 0.696 & & 0.683 & & 0.677 & & 0.680 \\
\hline Adjusted R-squared & & 0.674 & & 0.698 & & 0.660 & & 0.636 & & 0.619 & & 0.613 & & 0.616 \\
\hline S.E. of regression & & 0.506 & & 0.487 & & 0.517 & & 0.535 & & 0.547 & & 0.552 & & 0.550 \\
\hline Sum squared resid & & 10.240 & & 9.489 & & 10.685 & & 11.450 & & 11.966 & & 12.168 & & 12.079 \\
\hline Log likelihood & & -31.173 & & -29.308 & & -32.216 & & -33.909 & & -34.989 & & -35.399 & & -35.219 \\
\hline F-statistic & & 13.419 & & 14.876 & & 12.651 & & 11.473 & & 10.763 & & 10.501 & & 10.615 \\
\hline Prob(F-statistic) & & 0.000 & & 0.000 & & 0.000 & & 0.000 & & 0.000 & & 0.000 & & 0.000 \\
\hline Mean dependent var & & 0.013 & & 0.013 & & 0.013 & & 0.013 & & 0.013 & & 0.013 & & 0.013 \\
\hline S.D. dependent var & & 0.887 & & 0.887 & & 0.887 & & 0.887 & & 0.887 & & 0.887 & & 0.887 \\
\hline Akaike info criterion & & 1.640 & & 1.564 & & 1.682 & & 1.751 & & 1.795 & & 1.812 & & 1.805 \\
\hline Schwarz criterion & & 1.987 & & 1.911 & & 2.030 & & 2.099 & & 2.143 & & 2.160 & & 2.152 \\
\hline Hannan-Quinn criter. & & 1.772 & & 1.695 & & 1.814 & & 1.883 & & 1.927 & & 1.944 & & 1.937 \\
\hline Durbin-Watson stat & & 1.914 & & 1.749 & & 1.702 & & 1.493 & & 1.520 & & 1.518 & & 1.521 \\
\hline
\end{tabular}


TABLE A5

Nominal Fiscal Deficit (DLNNETDEF) - with "PDcycle" variables

\begin{tabular}{|c|c|c|c|c|c|c|c|c|c|c|c|c|}
\hline \multicolumn{13}{|c|}{$\begin{array}{l}\text { ARMA model: } \quad \text { DLNNETDEF }= \\
M A(1)=-0.218, M A(2)=0.938]\end{array}$} \\
\hline \multirow{2}{*}{\begin{tabular}{|l|} 
Estimated model \\
Explanatory variables
\end{tabular}} & \multicolumn{2}{|c|}{ Model 28} & \multicolumn{2}{|c|}{ Model 29} & \multicolumn{2}{|c|}{ Model 30} & \multicolumn{2}{|c|}{ Model 31} & \multicolumn{2}{|c|}{ Model 32} & \multicolumn{2}{|c|}{ Model 33} \\
\hline & Coeff. & Sig. & Coeff. & Sig. & Coeff. & Sig. & Coeff. & Sig. & Coeff. & Sig. & Coeff. & Sig. \\
\hline $\mathrm{C}$ & -0.085 & 0.416 & -0.005 & 0.965 & 0.003 & 0.970 & 0.003 & 0.970 & -0.166 & 0.011 & -0.150 & 0.057 \\
\hline DUM_2011Q1 & -0.164 & 0.789 & 0.194 & 0.753 & 0.194 & 0.753 & 0.194 & 0.753 & 0.068 & 0.876 & -0.267 & 0.594 \\
\hline DUM_2011Q2 & 0.802 & 0.185 & 0.418 & 0.491 & 0.428 & 0.479 & 0.428 & 0.479 & 0.858 & 0.051 & 1.113 & 0.039 \\
\hline $\operatorname{AR}(2)$ & -1.095 & 0.000 & -1.157 & 0.000 & -1.157 & 0.000 & -1.157 & 0.000 & -0.969 & 0.000 & -1.009 & 0.000 \\
\hline $\operatorname{AR}(4)$ & -0.308 & 0.055 & -0.281 & 0.043 & -0.281 & 0.043 & -0.281 & 0.043 & -0.306 & 0.024 & -0.299 & 0.062 \\
\hline MA(1) & -0.375 & 0.001 & -0.218 & 0.000 & -0.218 & 0.000 & -0.218 & 0.000 & -0.995 & 0.000 & -0.707 & 0.000 \\
\hline $\mathrm{MA}(2)$ & 0.811 & 0.000 & 0.938 & 0.000 & 0.938 & 0.000 & 0.938 & 0.000 & 0.927 & 0.000 & 0.695 & 0.000 \\
\hline PDcycle $_{1}$ & 0.0233 & 0.321 & & & & & & & & & & \\
\hline PDcycle $_{2}$ & & & 0.006 & 0.833 & & & & & & & & \\
\hline $\mathrm{PDcycle}_{3}$ & & & & & 0.010 & 0.824 & & & & & & \\
\hline $\mathrm{PDcycle}_{4}$ & & & & & & & 0.003 & 0.824 & & & & \\
\hline PDcycle $_{5}$ & & & & & & & & & 0.016 & 0.001 & & \\
\hline PDcycle $_{6}$ & & & & & & & & & & & 0.027 & 0.018 \\
\hline \multicolumn{13}{|c|}{ Diagnostic tests } \\
\hline R-squared & & 0.605 & & 0.609 & & 0.609 & & 0.609 & & 0.680 & & 0.638 \\
\hline Adjusted R-squared & & 0.538 & & 0.542 & & 0.542 & & 0.542 & & 0.626 & & 0.576 \\
\hline S.E. of regress sion & & 0.603 & & 0.600 & & 0.600 & & 0.600 & & 0.542 & & 0.577 \\
\hline Sum squared resid & & 14.895 & & 14.760 & & 14.758 & & 14.758 & & 12.065 & & 13.663 \\
\hline Log likelihood & & -40.354 & & -40.130 & & -40.127 & & -40.127 & & -35.191 & & -38.238 \\
\hline F-statistic & & 8.976 & & 9.113 & & 9.114 & & 9.114 & & 12.456 & & 10.314 \\
\hline Prob(F-statistic) & & 0.000 & & 0.000 & & 0.000 & & 0.000 & & 0.000 & & 0.000 \\
\hline Mean dependent var & & 0.013 & & 0.013 & & 0.013 & & 0.013 & & 0.013 & & 0.013 \\
\hline S.D. dependent var & & 0.887 & & 0.887 & & 0.887 & & 0.887 & & 0.887 & & 0.887 \\
\hline Akaike info criterion & & 1.974 & & 1.964 & & 1.964 & & 1.964 & & 1.763 & & 1.887 \\
\hline Schwarz criterion & & 2.283 & & 2.273 & & 2.273 & & 2.273 & & 2.072 & & 2.196 \\
\hline Hannan-Quinn criter. & & 2.091 & & 2.082 & & 2.082 & & 2.082 & & 1.880 & & 2.004 \\
\hline Durbin-Watson stat & & 2.130 & & 2.357 & & 2.357 & & 2.357 & & 1.514 & & 1.819 \\
\hline
\end{tabular}


TABLE A6

Nominal Fiscal Deficit (DLNNETDEF) - with "PDcycle" variables

ARMA model: $D L N N E T D E F=0.015+0.210^{*} D U M \_2011 Q 1+0.425^{*} D U M \_2011 Q 2+[A R(2)=-1.154, A R(4)=-0.279$, $M A(1)=-0.218, M A(2)=0.938]$

\begin{tabular}{|c|c|c|c|c|c|c|c|c|c|c|c|c|}
\hline \multirow{2}{*}{$\frac{\text { Estimated model }}{\text { Explanatory variables }}$} & \multicolumn{2}{|c|}{ Model 34} & \multicolumn{2}{|c|}{ Model 35} & \multicolumn{2}{|c|}{ Model 36} & \multicolumn{2}{|c|}{ Model 37} & \multicolumn{2}{|c|}{ Model 38} & \multicolumn{2}{|c|}{ Model 39} \\
\hline & Coeff. & Sig. & Coeff. & Sig. & Coeff. & Sig. & Coeff. & Sig. & Coeff. & Sig. & Coeff. & Sig. \\
\hline $\mathrm{C}$ & -0.072 & 0.240 & -0.056 & 0.310 & 0.042 & 0.628 & 0.104 & 0.193 & 0.081 & 0.232 & 0.043 & 0.544 \\
\hline DUM_2011Q1 & -0.333 & 0.533 & -0.317 & 0.559 & 0.267 & 0.668 & -0.002 & 0.997 & -0.030 & 0.958 & -0.126 & 0.833 \\
\hline DUM_2011Q2 & 0.987 & 0.075 & 1.058 & 0.058 & 0.424 & 0.483 & 0.857 & 0.131 & 0.834 & 0.142 & 0.823 & 0.157 \\
\hline $\operatorname{AR}(2)$ & -0.977 & 0.000 & -0.943 & 0.000 & -1.144 & 0.000 & -0.922 & 0.000 & -0.939 & 0.000 & -0.939 & 0.000 \\
\hline $\operatorname{AR}(4)$ & -0.253 & 0.131 & -0.204 & 0.220 & -0.268 & 0.055 & -0.182 & 0.303 & -0.202 & 0.250 & -0.198 & 0.268 \\
\hline $\mathrm{MA}(1)$ & -0.630 & 0.000 & -0.605 & 0.000 & -0.218 & 0.000 & -0.588 & 0.000 & -0.582 & 0.001 & -0.529 & 0.001 \\
\hline $\mathrm{MA}(2)$ & 0.679 & 0.000 & 0.703 & 0.000 & 0.938 & 0.000 & 0.640 & 0.000 & 0.636 & 0.000 & 0.645 & 0.000 \\
\hline $\mathrm{PDcycle}_{7}$ & 0.018 & 0.061 & & & & & & & & & & \\
\hline Pdcycle $_{8}$ & & & 0.027 & 0.046 & & & & & & & & \\
\hline $\mathrm{PDcycle}_{9}$ & & & & & -0.009 & 0.650 & & & & & & \\
\hline PDcycle $_{10}$ & & & & & & & -0.016 & 0.170 & & & & \\
\hline PDcycle $_{11}$ & & & & & & & & & -0.026 & 0.190 & & \\
\hline PDcycle $_{12}$ & & & & & & & & & & & -0.009 & 0.541 \\
\hline \multicolumn{13}{|c|}{ Diagnostic tests } \\
\hline R-squared & & 0.623 & & 0.626 & & 0.610 & & 0.610 & & 0.608 & & 0.595 \\
\hline Adjusted R-squared & & 0.559 & & 0.562 & & 0.544 & & 0.544 & & 0.541 & & 0.526 \\
\hline S.E. of regression & & 0.589 & & 0.587 & & 0.599 & & 0.599 & & 0.600 & & 0.610 \\
\hline Sum squared resid & & 14.215 & & 14.112 & & 14.699 & & 14.705 & & 14.777 & & 15.273 \\
\hline Log likelihood & & -39.209 & & -39.030 & & -40.029 & & -40.039 & & -40.159 & & -40.968 \\
\hline F-statistic & & 9.686 & & 9.800 & & 9.174 & & 9.168 & & 9.095 & & 8.609 \\
\hline Prob(F-statistic) & & 0.000 & & 0.000 & & 0.000 & & 0.000 & & 0.000 & & 0.000 \\
\hline Mean dependent var & & 0.013 & & 0.013 & & 0.013 & & 0.013 & & 0.013 & & 0.013 \\
\hline S.D. dependent var & & 0.887 & & 0.887 & & 0.887 & & 0.887 & & 0.887 & & 0.887 \\
\hline Akaike info criterion & & 1.927 & & 1.920 & & 1.960 & & 1.961 & & 1.966 & & 1.999 \\
\hline Schwarz criterion & & 2.236 & & 2.228 & & 2.269 & & 2.270 & & 2.275 & & 2.308 \\
\hline Hannan-Quinn criter. & & 2.044 & & 2.037 & & 2.078 & & 2.078 & & 2.083 & & 2.116 \\
\hline Durbin-Watson stat & & 1.813 & & 1.773 & & 2.332 & & 1.741 & & 1.772 & & 1.799 \\
\hline
\end{tabular}


TABLE A7

Fiscal Deficit to GDP (DNETDEF_GDP) - with "PDcum" variables (before Election)

\begin{tabular}{|c|c|c|c|c|c|c|c|c|c|c|c|c|c|c|c|c|}
\hline \multirow{2}{*}{$\begin{array}{l}\text { Estimated model } \\
\text { Explanatory variables }\end{array}$} & \multicolumn{2}{|c|}{ Model 40} & \multicolumn{2}{|c|}{ Model 41} & \multicolumn{2}{|c|}{ Model 42} & \multicolumn{2}{|c|}{ Model 43} & \multicolumn{2}{|c|}{ Model 44} & \multicolumn{2}{|c|}{ Model 45} & \multicolumn{2}{|c|}{ Model 46} & \multicolumn{2}{|c|}{ Model 47} \\
\hline & Coeff. & Sig. & Coeff. & Sig. & Coeff. & Sig. & Coeff. & Sig. & Coeff. & Sig. & Coeff. & Sig. & Coeff. & Sig. & Coeff. & Sig. \\
\hline $\mathrm{C}$ & -0.182 & 0.256 & -0.373 & 0.034 & -0.392 & 0.025 & -0.413 & 0.021 & -0.424 & 0.022 & -0.474 & 0.015 & -0.523 & 0.010 & -0.585 & 0.006 \\
\hline DUM_2011Q1 & -0.141 & 0.963 & 0.764 & 0.779 & 0.784 & 0.773 & 0.838 & 0.758 & 0.874 & 0.750 & 0.994 & 0.713 & 1.099 & 0.683 & 1.246 & 0.640 \\
\hline DUM_2011Q2 & 1.432 & 0.634 & 1.534 & 0.570 & 1.559 & 0.564 & 1.612 & 0.551 & 1.643 & 0.546 & 1.770 & 0.511 & 1.882 & 0.482 & 2.037 & 0.443 \\
\hline $\operatorname{AR}(4)$ & 0.591 & 0.000 & 0.638 & 0.000 & 0.622 & 0.000 & 0.623 & 0.000 & 0.626 & 0.000 & 0.634 & 0.000 & 0.633 & 0.000 & 0.642 & 0.000 \\
\hline MA(1) & -0.956 & 0.000 & -0.959 & 0.000 & -0.959 & 0.000 & -0.960 & 0.000 & -0.961 & 0.000 & -0.962 & 0.000 & -0.963 & 0.000 & -0.965 & 0.000 \\
\hline Pdcume & 0.975 & 0.491 & & & & & & & & & & & & & & \\
\hline PDcum $_{1}$ & & & 3.179 & 0.014 & & & & & & & & & & & & \\
\hline PDcum $_{2}$ & & & & & 1.8117 & 0.010 & & & & & & & & & & \\
\hline PDcum $_{3}$ & & & & & & & 1.325 & 0.009 & & & & & & & & \\
\hline PDcum $_{4}$ & & & & & & & & & 1.050 & 0.012 & & & & & & \\
\hline PDcum $_{5}$ & & & & & & & & & & & 0.994 & 0.007 & & & & \\
\hline PDcum $_{6}$ & & & & & & & & & & & & & 0.975 & 0.005 & & \\
\hline PDcum $_{7}$ & & & & & & & & & & & & & & & 0.991 & 0.003 \\
\hline \multicolumn{17}{|c|}{ Diagnostic tests } \\
\hline R-squared & & 0.575 & & 0.628 & & 0.633 & & 0.634 & & 0.628 & & 0.635 & & 0.641 & & 0.647 \\
\hline Adjusted R-squared & & 0.525 & & 0.585 & & 0.590 & & 0.591 & & 0.585 & & 0.593 & & 0.599 & & 0.606 \\
\hline S.E. of regression & & 3.211 & & 3.003 & & 2.984 & & 2.981 & & 3.002 & & 2.974 & & 2.950 & & 2.924 \\
\hline Sum squared resid & & 443.283 & & 387.711 & & 382.859 & & 382.049 & & 387.490 & & 380.312 & & 374.232 & & 367.526 \\
\hline Log likelihood & & -123.487 & & -120.205 & & -119.896 & & -119.844 & & -120.191 & & -119.733 & & -119.338 & & -118.895 \\
\hline F-statistic & & 11.625 & & 14.523 & & 14.816 & & 14.866 & & 14.537 & & 14.973 & & 15.356 & & 15.793 \\
\hline Prob(F-statistic) & & 0.000 & & 0.000 & & 0.000 & & 0.000 & & 0.000 & & 0.000 & & 0.000 & & 0.000 \\
\hline Mean dependent var & & -0.006 & & -0.006 & & -0.006 & & -0.006 & & -0.006 & & -0.006 & & -0.006 & & -0.006 \\
\hline S.D. dependent var & & 4.660 & & 4.660 & & 4.660 & & 4.660 & & 4.660 & & 4.660 & & 4.660 & & 4.660 \\
\hline Akaike info criterion & & 5.285 & & 5.151 & & 5.139 & & 5.137 & & 5.151 & & 5.132 & & 5.116 & & 5.098 \\
\hline Schwarz criterion & & 5.517 & & 5.383 & & 5.370 & & 5.368 & & 5.382 & & 5.364 & & 5.347 & & 5.329 \\
\hline Hannan-Quinn criter. & & 5.373 & & 5.239 & & 5.227 & & 5.224 & & 5.239 & & 5.220 & & 5.204 & & 5.186 \\
\hline Durbin-Watson stat & & 1.666 & & 1.722 & & 1.804 & & 1.816 & & 1.852 & & 1.858 & & 1.890 & & 1.920 \\
\hline
\end{tabular}


TABLE A9

Fiscal Deficit to GDP (DNETDEF_GDP) - with "PDy" variables

ARMA model: DNETDEF_GDP $=-0.1061+0.2176^{*} D U M_{-} 2011 Q 1+$ $0.8794 * D U M \_2011 Q 2+[A R(4)=0.5765, M A(1)=-0.9545]$

\begin{tabular}{|c|c|c|c|c|c|c|c|c|}
\hline \multirow{2}{*}{$\begin{array}{l}\text { Estimated model } \\
\text { Explanatory variables }\end{array}$} & \multicolumn{2}{|c|}{ Model 56} & \multicolumn{2}{|c|}{ Model 57} & \multicolumn{2}{|c|}{ Model 58} & \multicolumn{2}{|c|}{ Model 59} \\
\hline & Coeff. & Sig. & Coeff. & Sig. & Coeff. & Sig. & Coeff. & Sig. \\
\hline $\mathrm{C}$ & -0.421 & 0.022 & -0.248 & 0.180 & 0.111 & 0.000 & 0.032 & 0.879 \\
\hline DUM_2011Q1 & 0.323 & 0.906 & 0.529 & 0.856 & 2.107 & 0.000 & -0.563 & 0.855 \\
\hline DUM_2011Q2 & 2.025 & 0.462 & 1.227 & 0.673 & 0.999 & 0.545 & 1.588 & 0.598 \\
\hline $\operatorname{AR}(4)$ & 0.627 & 0.000 & 0.588 & 0.000 & 0.629 & 0.489 & 0.567 & 0.000 \\
\hline $\operatorname{MA}(1)$ & -0.961 & 0.000 & -0.957 & 0.000 & -0.947 & 0.718 & -0.962 & 0.000 \\
\hline $\mathrm{PDy}_{-1}$ & 1.010 & 0.018 & & & & & & \\
\hline $\mathrm{PDy}_{-2}$ & & & 0.574 & 0.199 & & & & \\
\hline $\mathrm{PDy}_{1}$ & & & & & -0.954 & 0.066 & & \\
\hline $\mathrm{PDy}_{2}$ & & & & & & & -0.508 & 0.291 \\
\hline \multicolumn{9}{|c|}{ Diagnostic tests } \\
\hline R-squared & & 0.624 & & 0.587 & & 0.609 & & 0.581 \\
\hline Adjusted R-squared & & 0.580 & & 0.538 & & 0.563 & & 0.532 \\
\hline S.E. of regression & & 3.020 & & 3.166 & & 3.079 & & 3.187 \\
\hline Sum squared resid & & 392.134 & & 430.989 & & 407.674 & & 436.820 \\
\hline Log likelihood & & -120.483 & & -122.797 & & -121.435 & & -123.127 \\
\hline F-statistic & & 14.263 & & 12.201 & & 13.391 & & 11.924 \\
\hline Prob(F-statistic) & & 0.000 & & 0.000 & & 0.000 & & 0.000 \\
\hline Mean dependent var & & -0.006 & & -0.006 & & -0.006 & & -0.006 \\
\hline S.D. dependent var & & 4.660 & & 4.660 & & 4.660 & & 4.660 \\
\hline Akaike info criterion & & 5.163 & & 5.257 & & 5.201 & & 5.270 \\
\hline Schwarz criterion & & 5.394 & & 5.489 & & 5.433 & & 5.502 \\
\hline Hannan-Quinn criter. & & 5.250 & & 5.345 & & 5.289 & & 5.358 \\
\hline Durbin-Watson stat & & 1.808 & & 1.702 & & 1.734 & & 1.687 \\
\hline
\end{tabular}


TABLE A10

Fiscal Deficit to GDP (DNETDEF_GDP) - with "PDsym" variables

ARMA model: $D N E T D E F \_G D P=-0.1061+0.2176 * D U M \_2011 Q 1+0.8794 * D U M \_2011 Q 2+[A R(4)=0.5765, M A(1)=-0.9545]$

\begin{tabular}{|c|c|c|c|c|c|c|c|c|c|c|c|c|c|c|}
\hline \multirow{2}{*}{$\frac{\text { Estimated model }}{\text { Explanatory variables }}$} & \multicolumn{2}{|c|}{ Model 60} & \multicolumn{2}{|c|}{ Model 61} & \multicolumn{2}{|c|}{ Model 62} & \multicolumn{2}{|c|}{ Model 63} & \multicolumn{2}{|c|}{ Model 64} & \multicolumn{2}{|c|}{ Model 65} & \multicolumn{2}{|c|}{ Model 66} \\
\hline & Coeff. & Sig. & Coeff. & Sig. & Coeff. & Sig. & Coeff. & Sig. & Coeff. & Sig. & Coeff. & Sig. & Coeff. & Sig. \\
\hline $\mathrm{C}$ & -0.150 & 0.401 & -0.244 & 0.253 & -0.230 & 0.313 & -0.212 & 0.391 & -0.166 & 0.554 & -0.119 & 0.736 & 0.216 & 0.721 \\
\hline DUM_2011Q1 & 0.652 & 0.826 & 1.813 & 0.524 & 2.401 & 0.410 & 1.999 & 0.474 & 1.741 & 0.522 & 1.479 & 0.575 & 1.166 & 0.650 \\
\hline DUM_2011Q2 & 1.412 & 0.629 & 1.426 & 0.600 & 1.306 & 0.626 & 2.036 & 0.442 & 2.443 & 0.357 & 2.779 & 0.291 & 3.063 & 0.243 \\
\hline $\mathrm{AR}(4)$ & 0.634 & 0.000 & 0.681 & 0.000 & 0.675 & 0.000 & 0.676 & 0.000 & 0.682 & 0.000 & 0.692 & 0.000 & 0.692 & 0.000 \\
\hline MA(1) & -0.955 & 0.000 & -0.956 & 0.000 & -0.954 & 0.000 & -0.954 & 0.000 & -0.956 & 0.000 & -0.960 & 0.000 & -0.962 & 0.000 \\
\hline PDsym $_{-1}$ & 2.740 & 0.118 & & & & & & & & & & & & \\
\hline PDsym $_{1}$ & -2.639 & 0.135 & & & & & & & & & & & & \\
\hline PDsym $_{2}$ & & & 1.896 & 0.012 & & & & & & & & & & \\
\hline $\mathrm{PDsym}_{2}$ & & & -1.521 & 0.050 & & & & & & & & & & \\
\hline PDsym $_{3}$ & & & & & 1.204 & 0.013 & & & & & & & & \\
\hline $\mathrm{PDsym}_{3}$ & & & & & -1.025 & 0.054 & & & & & & & & \\
\hline $\mathrm{PDsym}_{-4}$ & & & & & & & 0.886 & 0.026 & & & & & & \\
\hline $\mathrm{PDsym}_{4}$ & & & & & & & -0.814 & 0.064 & & & & & & \\
\hline PDsym $_{5}$ & & & & & & & & & 0.665 & 0.078 & & & & \\
\hline PDsym$_{5}$ & & & & & & & & & -0.745 & 0.077 & & & & \\
\hline PDsym_-6 $_{-6}$ & & & & & & & & & & & 0.529 & 0.198 & & \\
\hline $\mathrm{PDsym}_{6}$ & & & & & & & & & & & -0.730 & 0.108 & & \\
\hline PDsym-7 & & & & & & & & & & & & & 0.121 & 0.851 \\
\hline $\mathrm{PDsym}_{7}$ & & & & & & & & & & & & & -1.030 & 0.134 \\
\hline \multicolumn{15}{|c|}{ Diagnostic tests } \\
\hline R-squared & & 0.597 & & 0.633 & & 0.647 & & 0.653 & & 0.653 & & 0.659 & & 0.665 \\
\hline Adjusted R-squared & & 0.539 & & 0.581 & & 0.596 & & 0.603 & & 0.603 & & 0.610 & & 0.618 \\
\hline S.E. of regression & & 3.164 & & 3.017 & & 2.961 & & 2.936 & & 2.936 & & 2.911 & & 2.882 \\
\hline Sum squared resid & & 420.524 & & 382.249 & & 368.206 & & 361.999 & & 362.062 & & 355.792 & & 348.835 \\
\hline Log likelihood & & -122.195 & & -119.857 & & -118.940 & & -118.524 & & -118.528 & & -118.100 & & -117.616 \\
\hline F-statistic & & 10.353 & & 12.090 & & 12.818 & & 13.158 & & 13.155 & & 13.510 & & 13.919 \\
\hline Prob(F-statistic) & & 0.000 & & 0.000 & & 0.000 & & 0.000 & & 0.000 & & 0.000 & & 0.000 \\
\hline Mean dependent var & & -0.006 & & -0.006 & & -0.006 & & -0.006 & & -0.006 & & -0.006 & & -0.006 \\
\hline S.D. dependent var & & 4.660 & & 4.660 & & 4.660 & & 4.660 & & 4.660 & & 4.660 & & 4.660 \\
\hline Akaike info criterion & & 5.273 & & 5.178 & & 5.140 & & 5.123 & & 5.124 & & 5.106 & & 5.086 \\
\hline Schwarz criterion & & 5.544 & & 5.448 & & 5.411 & & 5.394 & & 5.394 & & 5.376 & & 5.357 \\
\hline Hannan-Quinn criter. & & 5.376 & & 5.280 & & 5.243 & & 5.226 & & 5.226 & & 5.209 & & 5.189 \\
\hline Durbin-Wats on stat & & 1.807 & & 1.878 & & 1.914 & & 1.936 & & 1.992 & & 2.008 & & 1.990 \\
\hline
\end{tabular}


TABLE A11

Fiscal Deficit to GDP (DNETDEF_GDP) - with "PDcycle" variables

\begin{tabular}{|c|c|c|c|c|c|c|c|c|c|c|c|c|}
\hline \multicolumn{13}{|c|}{$\begin{array}{l}\text { ARMA model: } D N E T D E F_{-} G D P=-0.106 \\
M A(1)=-0.9545]\end{array}$} \\
\hline Estimated model & \multicolumn{2}{|c|}{ Model 67} & \multicolumn{2}{|c|}{ Model 68} & \multicolumn{2}{|c|}{ Model 69} & \multicolumn{2}{|c|}{ Model 70} & \multicolumn{2}{|c|}{ Model 71} & \multicolumn{2}{|c|}{ Model 72} \\
\hline Explanatory variables & Coeff. & Sig. & Coeff. & Sig. & Coeff. & Sig. & Coeff. & Sig. & Coeff. & Sig. & Coeff. & Sig. \\
\hline $\mathrm{C}$ & -0.367 & 0.237 & -0.195 & 0.497 & -0.175 & 0.355 & -0.175 & 0.355 & -0.969 & 0.001 & -0.908 & 0.003 \\
\hline DUM_2011Q1 & -0.302 & 0.921 & 0.000 & 1.000 & -0.106 & 0.973 & -0.106 & 0.973 & 0.450 & 0.862 & -0.333 & 0.902 \\
\hline DUM_2011Q2 & 1.300 & 0.661 & 1.003 & 0.736 & 1.131 & 0.706 & 1.131 & 0.706 & 3.277 & 0.218 & 3.245 & 0.246 \\
\hline $\operatorname{AR}(4)$ & 0.577 & 0.000 & 0.575 & 0.000 & 0.576 & 0.000 & 0.576 & 0.000 & 0.675 & 0.000 & 0.642 & 0.000 \\
\hline $\mathrm{MA}(1)$ & -0.959 & 0.000 & -0.956 & 0.000 & -0.956 & 0.000 & -0.956 & 0.000 & -0.965 & 0.000 & -0.966 & 0.000 \\
\hline PDcycle $_{1}$ & 0.062 & 0.417 & & & & & & & & & & \\
\hline PDcycle $_{2}$ & & & 0.024 & 0.763 & & & & & & & & \\
\hline $\mathrm{PDcycle}_{3}$ & & & & & 0.0505 & 0.691 & & & & & & \\
\hline $\mathrm{PDcycle}_{4}$ & & & & & & & 0.017 & 0.691 & & & & \\
\hline PDcycle $_{5}$ & & & & & & & & & 0.070 & 0.002 & & \\
\hline PDcycle $_{6}$ & & & & & & & & & & & 0.122 & 0.009 \\
\hline \multicolumn{13}{|c|}{ Diagnostic tests } \\
\hline R-squared & & 0.578 & & 0.571 & & 0.572 & & 0.572 & & 0.655 & & 0.635 \\
\hline Adjusted R-squared & & 0.528 & & 0.521 & & 0.522 & & 0.522 & & 0.615 & & 0.592 \\
\hline S.E. of regression & & 3.200 & & 3.226 & & 3.223 & & 3.223 & & 2.891 & & 2.975 \\
\hline Sum squared resid & & 440.399 & & 447.510 & & 446.638 & & 446.638 & & 359.336 & & 380.562 \\
\hline Log likelihood & & -123.327 & & -123.719 & & -123.671 & & -123.671 & & -118.343 & & -119.749 \\
\hline F-statistic & & 11.757 & & 11.433 & & 11.473 & & 11.473 & & 16.349 & & 14.958 \\
\hline Prob(F-statistic) & & 0.000 & & 0.000 & & 0.000 & & 0.000 & & 0.000 & & 0.000 \\
\hline Mean dependent var & & -0.006 & & -0.006 & & -0.006 & & -0.006 & & -0.006 & & -0.006 \\
\hline S.D. dependent var & & 4.660 & & 4.660 & & 4.660 & & 4.660 & & 4.660 & & 4.660 \\
\hline Akaike info criterion & & 5.279 & & 5.295 & & 5.293 & & 5.293 & & 5.075 & & 5.133 \\
\hline Schwarz criterion & & 5.510 & & 5.526 & & 5.524 & & 5.524 & & 5.307 & & 5.364 \\
\hline Hannan-Quinn criter. & & 5.367 & & 5.383 & & 5.381 & & 5.381 & & 5.163 & & 5.220 \\
\hline Durbin-Watson stat & & 1.657 & & 1.629 & & 1.632 & & 1.632 & & 1.982 & & 1.897 \\
\hline
\end{tabular}


TABLE A12

Fiscal Deficit to GDP (DNETDEF GDP) - with "PDcycle" variables

ARMA model: $D N E T D E F \_G D P=-0.1061+0.2176^{*} D U M \_2011 Q 1+0.8794 * D U M \_2011 Q 2+[A R(4)=0.5765$, $M A(1)=-0.9545]$

\begin{tabular}{|c|c|c|c|c|c|c|c|c|c|c|c|c|}
\hline \multirow{2}{*}{$\begin{array}{l}\text { Estimated model } \\
\text { Explanatory variables }\end{array}$} & \multicolumn{2}{|c|}{ Model 73} & \multicolumn{2}{|c|}{ Model 74} & \multicolumn{2}{|c|}{ Model 75} & \multicolumn{2}{|c|}{ Model 76} & \multicolumn{2}{|c|}{ Model 77} & \multicolumn{2}{|c|}{ Model 78} \\
\hline & Coeff. & Sig. & Coeff. & Sig. & Coeff. & Sig. & Coeff. & Sig. & Coeff. & Sig. & Coeff. & Sig. \\
\hline $\mathrm{C}$ & -0.462 & 0.031 & -0.321 & 0.080 & -0.110 & 0.586 & 0.294 & 0.281 & 0.232 & 0.311 & 0.044 & 0.847 \\
\hline DUM_2011Q1 & -0.481 & 0.868 & -0.338 & 0.909 & 0.196 & 0.951 & 1.510 & 0.618 & 1.518 & 0.612 & 0.873 & 0.782 \\
\hline DUM_2011Q2 & 2.121 & 0.463 & 1.747 & 0.550 & 0.893 & 0.766 & 0.926 & 0.743 & 0.978 & 0.728 & 0.698 & 0.812 \\
\hline $\operatorname{AR}(4)$ & 0.603 & 0.000 & 0.596 & 0.000 & 0.576 & 0.000 & 0.613 & 0.000 & 0.614 & 0.000 & 0.588 & 0.000 \\
\hline MA(1) & -0.963 & 0.000 & -0.959 & 0.000 & -0.955 & 0.000 & -0.950 & 0.000 & -0.951 & 0.000 & -0.952 & 0.000 \\
\hline PDcycle $_{7}$ & 0.066 & 0.081 & & & & & & & & & & \\
\hline Pdcycle $_{8}$ & & & 0.073 & 0.172 & & & & & & & & \\
\hline PDcycle $_{9}$ & & & & & 0.0012 & 0.983 & & & & & & \\
\hline PDcycle $_{10}$ & & & & & & & -0.065 & 0.136 & & & & \\
\hline PDcycle $_{11}$ & & & & & & & & & -0.120 & 0.108 & & \\
\hline PDcycle $_{12}$ & & & & & & & & & & & -0.037 & 0.501 \\
\hline \multicolumn{13}{|c|}{ Diagnostic tests } \\
\hline R-squared & & 0.602 & & 0.590 & & 0.570 & & 0.596 & & 0.599 & & 0.575 \\
\hline Adjusted R-squared & & 0.556 & & 0.543 & & 0.520 & & 0.549 & & 0.553 & & 0.526 \\
\hline S.E. of regression & & 3.105 & & 3.152 & & 3.230 & & 3.130 & & 3.117 & & 3.209 \\
\hline Sum squared resid & & 414.581 & & 427.104 & & 448.665 & & 421.330 & & 417.886 & & 442.704 \\
\hline Log likelihood & & -121.847 & & -122.576 & & -123.782 & & -122.242 & & -122.041 & & -123.455 \\
\hline F-statistic & & 13.025 & & 12.391 & & 11.382 & & 12.678 & & 12.854 & & 11.651 \\
\hline Prob(F-statistic) & & 0.000 & & 0.000 & & 0.000 & & 0.000 & & 0.000 & & 0.000 \\
\hline Mean dependent var & & -0.006 & & -0.006 & & -0.006 & & -0.006 & & -0.006 & & -0.006 \\
\hline S.D. dependent var & & 4.660 & & 4.660 & & 4.660 & & 4.660 & & 4.660 & & 4.660 \\
\hline Akaike info criterion & & 5.218 & & 5.248 & & 5.297 & & 5.234 & & 5.226 & & 5.284 \\
\hline Schwarz criterion & & 5.450 & & 5.480 & & 5.529 & & 5.466 & & 5.458 & & 5.516 \\
\hline Hannan-Quinn criter. & & 5.306 & & 5.336 & & 5.385 & & 5.322 & & 5.314 & & 5.372 \\
\hline Durbin-Watson stat & & 1.749 & & 1.692 & & 1.623 & & 1.698 & & 1.716 & & 1.634 \\
\hline
\end{tabular}


